\title{
PARTICIPACIÓN LABORAL DE LAS MUJERES EN EL MUNICIPIO DE POPAYÁN (COLOMBIA)*
}

\author{
ALEJANDRA MILLER RESTREPO**, JULIANA ISABEL SARMIENTO CASTILLO**** \\ \& ANDRÉS MAURICIO GÓMEZ SÁNCHEZ***** \\ UNIVERSIDAD DEL CAUCA
}

Recibido/ Received/ Recebido: 17/03/2014 - Aceptado/ Accepted / Aprovado: 12/08/2014

\begin{abstract}
Resumen
El presente artículo busca indagar por la participación laboral de las mujeres -especialmente en situación de pobreza- en el municipio de Popayán (Colombia) entre los años 2007-2011. Para tal efecto, se realizó un análisis de la información suministrada por la Gran Encuesta Integrada de Hogares $(\mathrm{GEIH})$ y por un taller participativo realizado con 90 mujeres desempleadas y en situación de pobreza a nivel local. Con estos datos se realizaron análisis econométricos a largo plazo a través del Filtro de Hodrick-Prescott, un análisis de cointegración de Johansen y un Test de Causalidad de Granger, para determinar la inserción laboral femenina y su relación con los ciclos económicos de Popayán. Los resultados muestran entre otras cosas, que en todos los indicadores laborales tradicionalmente utilizados, las mujeres se encuentran siempre en desventaja frente a los hombres, situación que se acentúa en mujeres bajo condición de pobreza. Adicionalmente, se encuentra que las mujeres buscan emplearse cuando el ciclo económico es recesivo y no lo hacen cuando es expansivo.

Palabra clave: Participación laboral, Mujeres, Desempleo, Discriminación laboral, Econometría.
\end{abstract}

\section{LABOUR PARTICIPATION OF WOMEN IN THE MUNICIPALITY OF POPAYÁN (COLOMBIA)}

\begin{abstract}
This article seeks to investigate the women's labor force participation, especially in situations of poverty in the town of Popayan (Colombia) between 2007-2011. To this end, an analysis of information provided by the Great Integrated Household Survey (GEIH) and a participatory workshop with 90 unemployed women, and in a poverty situation to the local level was performed. With these data there were performed long terms econometric analyses through the Hodrick-Prescott filter, an
\end{abstract}

* Artículo de investigación derivado del proyecto denominado "Análisis del trabajo y el desempleo de las mujeres en situación de pobreza de la ciudad de Popayán 2007 - 2013" realizado en el último semestre de 2013, en el marco del Observatorio Regional del Mercado de Trabajo. Financiado por el Observatorio del Mercado Laboral del Cauca (2013-2014). Los autores agradecen al Departamento de la Prosperidad Social, al Ministerio de Trabajo, al Plan de Naciones Unidas para el Desarrollo y a la Universidad del Cauca.

** Economista, Universidad del Valle, sede Cali. Magíster en Ciencias Políticas, Universidad Javeriana, sede Cali. Candidata a Ph.D en Paz y Gestión de Conflictos, Universidad de Granada (España). Docente Asocida, Departamento de Economía, Universidad del Cauca. Miembro del Grupo de Investigación Entropía, Universidad del Cauca. Correo electrónico: amiller@unicauca.edu.co. Tel: 8209800 Ext. 3119. Dirección postal: Calle 5 No. 4-70, Popayán (Colombia).

**** Economista, Universidad del Cauca. Candidata a Ph.D en Economía Ecológica, Universidad del Cauca. Docente catedrática, Departamento de Economía, Universidad del Cauca. Miembro del Grupo de Investigación Entropía, Universidad del Cauca. Correo electrónico: jisarmiento@gmail.com

***** Economista, Universidad del Valle, sede Cali. Especialista en Gerencia de Proyectos, Universidad del Cauca. Magíster en Economía Aplicada, Universidad del Valle. Docente Titular, Departamento de Economía, Universidad del Cauca. Miembro del Grupo de Investigación Entropía, Universidad del Cauca. Correo electrónico: amgomez@unicauca.edu.co 
analysis of Johansen cointegration and a Granger causality test to determine the female labor force and its relation to Popayan economic cycles. The results show among other things, that in all labor indicators used traditionally, women are always at a disadvantage compared to men, a situation that is accentuated in women under poverty. Additionally, we found that women seek employment when the economic cycle is recessive and they do not do it when it is expansive.

Keywords: Labor participation, Women, Unemployment, Employment discrimination, Econometrics.

\title{
PARTICIPAÇÃO LABORAL DAS MULHERES NO MUNICÍPIO DE POPAYÁN (COLÔMBIA)
}

\begin{abstract}
Resumo
O presente artigo procura indagar pela participação laboral das mulheres - especialmente em situação de pobreza - no município de Popayán (Colômbia) entre os anos 2007-2011. Para tal efeito, realizou-se uma análise da informação fornecida pela Grande Enquete Integrada de Lares (GEIH) e por uma oficina participativa realizada com 90 mulheres desempregadas e em situação de pobreza a nível local. Com estes dados realizaram-se análises econométricos de longo prazo através do Filtro de Hodrick-Prescott, uma análise de Cointegração de Johansen e um Teste de Causalidade de Granger, para determinar a inserção laboral feminina e sua relação com os ciclos econômicos de Popayán. Os resultados mostram entre outras coisas, que em todos os indicadores laborais tradicionalmente utilizados, as mulheres se encontram sempre em desvantagem em relação aos homens, situação que se acentua em mulheres sob condição de pobreza. Adicionalmente, encontra-se que as mulheres procuram se empregar quando o ciclo econômico é recessivo e não o fazem quando é expansivo.
\end{abstract}

Palavras chave: Participação laboral, Mulheres, Desemprego, Discriminação laboral, Econometria.

Restrepo, A., Sarmiento, J. \& Gómez, A. (2015). Participación laboral de las mujeres en el municipio de Popayán (Colombia). En: Revista de la Facultad de Ciencias Económicas de la Universidad Militar Nueva Granada. rev.fac.cienc.econ, XXIII (1).

JEL: E27, E30, J71, C10.

\section{Introducción}

El Observatorio Regional del Mercado de Trabajo para Popayán (ORMET) ha realizado diversas investigaciones en la región sobre el comportamiento del mercado laboral. Atendiendo a los hallazgos de la investigación "Análisis del trabajo y el desempleo de las mujeres en situación de pobreza de la ciudad de Popayán 2007 - 2013" se constató que el desempleo de las mujeres en Popayán superaba ampliamente el desempleo, de por sí alto, de los hombres de la ciudad. Dicha circunstancia impulsó la propuesta de profundizar en el análisis del trabajo de las mujeres, poniendo especial énfasis en las mujeres en situación de pobreza del municipio. ${ }^{1}$

Teniendo en cuenta lo anterior, el presente estudio se enmarca en el análisis socioeconómico del traba-

1 Popayán es es una ciudad ubicada al suroccidente de Colombia, y es la capital del Departamento del Cauca. La ciudad está dividida en 9 comunas, las cuales albergan alrededor de 270.000 habitantes ( $88 \%$ es población urbana). Su economía se basa en el sector comercial y en el de servicios, con una baja participación del sector industrial. Es reconocida por la preservación de su arquitectura colonial y sus festividades de carácter religioso. 
jo de las mujeres de Popayán, teniendo en cuenta el enfoque de la economía feminista, que evidencia la manera cómo la división socio-sexual del trabajo, ha recargado en las mujeres el trabajo doméstico y reproductivo. Este enfoque reconoce adicionalmente el aporte del trabajo de las mujeres como aspecto vital para el cuidado de la fuerza de trabajo, pero también los obstáculos que éste representa para su inserción en la esfera laboral. En esta perspectiva, la investigación parte de la reflexión en torno a problemas y situaciones como las restricciones familiares que enfrentan las mujeres de cara a su inserción al mercado laboral, la doble jornada producto de la naturalización de lo reproductivo como una responsabilidad exclusiva de las mujeres, la jefatura femenina de los hogares, la feminización de la pobreza, y otros aspectos que necesariamente impactan en las posibilidades de las mujeres de obtener ingresos y acceder en condiciones de equidad a diferentes recursos.

En este orden de consideraciones, el documento consta de cinco partes, donde la primera es esta introducción. En segundo lugar se exponen algunos lineamientos teórico-conceptuales en torno al trabajo en las mujeres. Posteriormente, se realiza una caracterización del empleo y el desempleo tanto en las mujeres payanesas en general como aquellas en situación de pobreza. A continuación, se implementan distintos análisis econométricos para capturar la participación laboral de las mujeres en el mercado de trabajo local. Finalmente se realizan un conjunto de conclusiones y recomendaciones.

\section{Marco teórico-conceptual}

El presente estudio, se enmarca en el análisis socioeconómico del trabajo de las mujeres de Popayán, a partir de dos niveles (Safa, 1992), el nivel objetivo, relacionado con los referentes económicos, políticos y sociales; y otro, el subjetivo, relacionado con la forma de ser, pensar y sentir de las mujeres. Partimos también de la existencia de dos aspectos centrales: uno, la prevalencia del patriarcado ${ }^{2}$ en todas las esferas en las que se desenvuelven las mujeres (privada, del mercado, pública), y dos, el reconocimiento del aporte a la economía que genera el trabajo doméstico, no valorado por las diferentes escuelas económicas en tanto no hace parte de las relaciones tradicionales de mercado. Este aporte del trabajo de las mujeres en la esfera doméstica y en la del mercado, puede resumirse, en términos económicos, al menos en dos aspectos, de un lado reduce el costo mercantil de la fuerza de trabajo lo que se traduce en transferencia de valor hacia el capital, aumentando la tasa de ganancia y, de otro, las mujeres constituyen una reserva de fuerza laboral mercantil que responde a las necesidades del régimen de producción flexible, que predomina actualmente en el sistema económico (Sarmiento \& Vargas, 2002).

\subsection{Trabajo y cuidado de la vida}

De acuerdo con Sarmiento \& Vargas (2002), el trabajo de las mujeres se realiza en el marco del proceso de la producción y reproducción societal ${ }^{3}$ que implica la producción de vida, el cuidado y formación de la fuerza de trabajo y, a la vez, la producción mercantil de bienes y servicios como medios de existencia. Es claro que el capital no considera la reproducción social (trabajo que fundamentalmente realizan las mujeres en Colombia y América Latina) como trabajo productivo, sin embargo, el análisis del trabajo de las mujeres debe contener no sólo factores económicos y políticos sino también sociales y culturales, que es donde radican las mayores diferencias con el trabajo realizado por los hombres.

La división socio-sexual del trabajo sitúa la crianza y el cuidado de las hijas y los hijos principalmente en las mujeres. Este trabajo es a la vez el proceso de socialización de los individuos y no se constituye sólo en una actividad material, representa fundamental-

2 El concepto de patriarcado plantea el poder masculino asociado a un sistema familiar y social, ideológico y político con el que los hombres a través de la fuerza, la presión directa, los rituales, la tradición, la ley o el lenguaje, las costumbres, la etiqueta, la educación y la división del trabajo determinan cuál es o no es el papel que las mujeres deben interpretar con el fin de estar en toda circunstancia sometidas al hombre (Amoros, 1991).

3 Se entiende la reproducción societal como un proceso dinámico que implica la reproducción biológica y de la fuerza de trabajo, de los bienes de consumo y de producción y la reproducción de las relaciones sociales, culturales, económicas, políticas y ambientales. 
mente las condiciones cotidianas para el desarrollo de la vida, y en consecuencia, el trabajo doméstico es esencial para que pueda realizarse el trabajo de mercado, es decir, el mercado sólo puede funcionar de la manera que lo hace, porque descansa, se apoya y depende del trabajo familiar (Carrasco, 2003).

Con la finalización del Estado de Bienestar, las mujeres ingresaron masivamente al mercado laboral, pero la asignación de las responsabilidades domésticas y de cuidado de la prole no se transformó significativamente, generando lo que se conoce como la "doble jornada" para las ellas es decir, además de ser fuerza productiva para el mercado y aportar con su salario al sostenimiento del hogar, las mujeres asumen simultáneamente las labores de sus casas, el cuidado de sus familias y hasta el de las comunidades. Es así como en las últimas décadas, surge una nueva forma de famila, en la que el hombre mantiene su rol pero en cambio la figura de ama de casa tradicional tiende a desaparecer, lo cual no significa que la mujer abandone su rol de cuidadora, sino que ahora cumple el doble rol.

\subsection{Economía feminista}

La separación entre producción y reproducción, es un factor hegemónico en la construcción de los modelos económicos actuales. Pero una mirada más compleja, ha dado lugar a otras formas de reflexionar la economía, en las que se tiene en cuenta que una parte muy significativa de ella, opera por fuera de los mecanismos de mercado y, por tanto, no termina de constituirse en una esfera separada (Quiroga, 2009).

La economía feminista aborda diversos temas ${ }^{4}$ y ha dado lugar a otras formas de reflexionar los proble- mas económicos. Busca develar la manera como los paradigmas tradicionales en economía tienen un sesgo androcéntrico tanto en los conceptos y categorías como en los marcos analíticos utilizados, afectándolas negativamente en la implementación de las políticas e invisibilizándolas en las estadísticas y los análisis económicos (Sarmiento \& Vargas, 2002). En palabras de Carrasco $(2003,4)$ :

\section{"La Economía Feminista no es un intento de ampliar los métodos y teorías existen- tes para incluir a las mujeres, tampoco consiste como ha afirmado Sandra Har- ding en la idea de "agregue mujeres y mezcle", se trata de algo más profundo, algo que pueda transformar la propia dis- ciplina y permita construir una economía que integre y analice la realidad de mu- jeres y hombres, teniendo como principio básico la satisfacción de las necesidades humanas".}

Desde el análisis del trabajo de las mujeres, la economía feminista aporta reflexiones en torno a los efectos que ha generado en ellas la flexibilización laboral en los procesos de producción, específicamente en la reducción del trabajo estable, la tercerización, el desarrollo tecnológico, y por otro, una desconcentración productiva basada en empresas medianas y pequeñas. Todo lo anterior, en el marco de un modelo de desarrollo y régimen de acumulación que ha precarizado aún más el trabajo femenino, al punto que actualmente una de las disyuntivas más fuertes para ellas no es empleo/ desempleo, sino empleo/precariedad ${ }^{5}$. Algunos efectos de este modelo en las condiciones del trabajo fe-

4 Según Carrasco (2003) entre las cuestiones tratadas se destacan: la crítica al pensamiento económico clásico por no considerar en sus estudios el trabajo de las mujeres, la discusión sobre el concepto de trabajo, las características y funciones del trabajo doméstico, distintos aspectos de la participación y discriminación laboral de las mujeres, las políticas económicas y sus efectos diferenciados por sexo, los problemas de género y desarrollo y, más recientemente, los efectos de la liberalización comercial y los flujos monetarios sobre el trabajo y condiciones de vida de las mujeres, la invisibilidad de las mujeres en los modelos macroeconómicos, el sesgo masculino presente en los ingresos y gastos de los presupuestos públicos, la crítica y nuevas propuestas a las estadísticas y a la contabilidad nacional por no incluir los trabajos no remunerados, los estudios sobre usos del tiempo que permiten constatar las diferencias de dedicación a los distintos trabajos entre mujeres y hombres y el mayor tiempo total de trabajo realizado por las mujeres y el desarrollo de nuevos enfoques que permitan el análisis global de la sociedad manteniendo como objeto central la sostenibilidad de la vida humana, el bienestar y la calidad de vida de las personas.

5 La precariedad se asocia a la inestabilidad, los bajos salarios, la segmentación del mercado, la temporalidad y la calidad y condiciones del puesto de trabajo, entre otras. 
menino y en las propias mujeres, identificados por Bustos citada por Sarmiento \& Vargas (2002) son:

- La política de bajos salarios que es empleada como ventaja competitiva para atraer capital nacional o extranjero a los territorios ha ocasionado que los ingresos monetarios de los hogares se hayan mermado considerablemente. Esta situación ha provocado que los hogares recurran a la mano de obra de mujeres, niños $y$ ancianos, para lograr subsistir o mantener su nivel de consumo.

- Si bien es cierto que en el marco del modelo se ha incrementado la actividad económica de las ellas, no es alentador saber que las condiciones de las mismas, lejos de mejorar, se reproducen, perpetuando la subordinación y la precariedad de las mujeres como trabajadoras.

- El modelo no contribuye a la construcción de las mujeres como trabajadoras plenas sino a la construcción de una identidad fragmentada, donde debe cumplir en condiciones de mayor precariedad los roles histórico-social-biológicos (maternidad y reproducción de la fuerza laboral) y de trabajadora proveedora de ingresos para el hogar.

- Reafirmación de los roles femeninos y masculinos en el hogar. En el caso de mujeres jefas de hogar las dificultades económicas son mayores, dando paso al fenómeno conocido como feminización de la pobreza.

- La clase trabajadora y las mujeres en particular, quienes tienen menos acceso a recursos, se ven cada día más desprotegidas debido al adelgazamiento del gasto social (educación, salud, vivienda, servicios públicos), y al persistente deterioro del salario real y el desmonte de la seguridad social.
- Distintas autoras (Loayza, 1997; Benería, 2006; Carrasco, 2003) han planteado igualmente, que en los momentos de crisis del sistema económico, como las crisis financieras ${ }^{6}$ del 2000 o del 2008, a las mujeres de los sectores medios y populares se les impone la responsabilidad de administrar los cambios adversos y minimizar con sus cuidados y trabajo los efectos generados en los hogares. Es así como en estos momentos recesivos del ciclo económico, las mujeres duplican sus horas de trabajo fundamentalmente en actividades de economía informal y del cuidado y protección a sus familias, o en muchas ocasiones el mismo Estado les asigna las labores de cuidado que deben asumir a cambio de salarios precarios (un ejemplo claro es el de las Madres Comunitarias en Colombia). El cuidado de la vida, realizado por las mujeres en sus hogares, se traslada ahora también al escenario de lo público, y se las ve actuando como las cuidadoras comunitarias de los niños y niñas, cuidadoras de la salud de las personas de la comunidad, promotoras centrales de los procesos educativos a través de las juntas de "padres" de familia, o activistas incansables de los procesos de consecución o construcción de viviendas; todas éstas, son actividades del cuidado que se realizan en el espacio público y que generalmente no son remuneradas, o tienen salarios muy bajos, como lo mencionábamos en párrafos anteriores.

Es imposible entonces analizar el mercado laboral, y particularmente el trabajo de ellas, de manera independiente de las familias. Para entender los aspectos socioeconómicos de su trabajo se requiere de un enfoque integrador que supere las tradicionales posturas binarias que han caracterizado a las escuelas económicas y avanzar en la consideración de las interrelaciones entre la actividad familiar y el trabajo de mercado. De acuerdo con Bakker (1999), para la comprensión adecuada de los temas del empleo y el trabajo de las mujeres, y para tener elementos más

6 Es importante anotar que autoras como Quiroga (2009), retoman como hecho fundamental, no las crisis financieras, sino lo que llama la "crisis de reproducción", referida a la exclusión sistemática de amplios sectores de la población, especialmente las mujeres, del acceso a los recursos indispensables para satisfacer sus necesidades de reproducción, biológica y social. En América Latina esta crisis se expresa en un conjunto de situaciones que por la vía del desempleo, la pobreza, la precariedad y diversas formas de discriminación impiden a una significativa parte de la población tener capacidad de acceder a los recursos necesarios para garantizar el desenvolvimiento de su vida personal y familiar, y su inclusión como ciudadanos con plenos derechos. 
claros para la elaboración de políticas diferenciales, es necesario reflexionar en torno a:

- Las restricciones familiares que enfrentan de cara al mercado laboral. Cabe destacar que, a diferencia de lo que sucede con los hombres, muchas mujeres deben "negociar" con sus parejas su decisión de buscar empleo, a lo que se suman las restricciones impuestas por los "tipos" de empleo que sus parejas aceptan o no. Así mismo, la búsqueda del cuidado de los hijos e hijas por parte de terceros para que ellas puedan trabajar en un empleo, o las restricciones que imponen los empleadores por el hecho de ser madres (asociadas a los supuestos inconvenientes que esta circunstancia acarrea en términos del tiempo que debe dedicar al cuidado de los hijos y no al trabajo), son factores familiares que afectan las decisiones y posibilidades de acceso al mercado laboral.

- La doble jornada. A pesar de la incursión en el mercado laboral, las labores domésticas y del cuidado no se redistribuyen en las familias y siguen siendo las ellas las que asumen este rol, extendiendo las horas trabajo, que en muchas ocasiones duplican la de los varones. Esta circunstancia acarrea efectos negativos en su salud debido al agotamiento crónico que muchas de ellas padecen, así como fuertes limitaciones en sus posibilidades de crecimiento educativo, desarrollo personal o participación ciudadana.

- La composición del hogar. La jefatura femenina ha aumentado en la última década en América Latina y en Colombia, y las estadísticas reflejan una correlación negativa entre el ingreso per cápita y la proporción de hogares que tienen como jefe a una mujer (Safa, 2002). Esto impone reflexiones específicas frente a las trabajadoras, y sus necesidades de provisión de servicios de cuidado de los hijos e hijas por parte de terceros. Igualmente debe analizarse que mientras los hombres jefes de hogar generalmente tienen el apoyo de una mujer para las actividades del cuidado (esposa, madre, etc.) en los hogares con jefatura femenina, generalmente no hay hombres que apoyen el trabajo del cuidado $y$ terminan siendo ellas las que asumen toda la responsabilidad.

- Las repercusiones por sexo de la cambiante organización del trabajo. Con el desmoronamiento del modelo de producción fordista que caracteriza a las economías latinoamericanas desde la década de los noventa hasta ahora, y la disminución del peso de la Industria en el PIB, así como la prevalente segmentación del mercado laboral por sexo, las mujeres aumentan su participación en el mercado laboral especialmente en el sector servicios. Se destaca que el servicio doméstico remunerado es materia casi exclusiva de la población femenina pero también otras formas de organización del trabajo como las maquilas, o los talleres en casa, han sido modalidades aplicadas casi de manera exclusiva a ellas, con efectos graves en términos del incremento de la precarización laboral.

Estos aspectos mencionados, deben ser analizados a la luz de la prevalencia del patriarcado, de la Naturalización de lo reproductivo como una responsabilidad exclusiva de las mujeres y de la separación que hace la economía entre producción y reproducción. Sólo de esta manera, se podrá hacer una aproximación real a las condiciones de inclusión o exclusión de ellas en el mercado laboral, asociadas a causas múltiples entre las que se encuentran las mismas características personales/individuales, la estructura del hogar y el acceso a recursos productivos, así como la estructura de la demanda del mercado laboral que en muchas ocasiones se constituye en una construcción social y simbólica de exigencias y subordinación de las ellas (Sarmiento \& Vargas, 2002).

\subsection{Sobre las políticas diferenciales de empleo}

Las decisiones de política económica en materia de generación de empleo para las mujeres están relacionadas con la intervención que deben hacer los gobiernos desde el nivel local, departamental y nacional, en el mercado de trabajo para disminuir el desempleo de las mujeres y mejorar las condiciones de permanecía y calidad de quienes ya tienen uno. Las políticas de empleo están necesariamente acompañadas de una movilización de recursos económicos, legales, técni- 
cos y humanos para la obtención de unos resultados concretos, y generalmente implica no sólo la esfera pública (administraciones municipales, departamentales, nacional) desde donde se promueve, sino también la esfera privada (entidades y empresas).

Algunas acciones que acompañan este tipo de políticas están relacionadas con la formación, la facilitación de canales para la inserción, la promoción de acciones contra las diversas violencias que se ejercen contra las mujeres y que se constituyen en una barrera de acceso al mercado laboral, para mencionar sólo algunas. Además de las decisiones de tipo macroeconómico, este tipo de acciones inciden sobre la demanda y la oferta de trabajo, fomentando la empleabilidad, el emprendimiento y la creación de nuevos empleos.

\section{Caracterización del trabajo de las mujeres en Popayán}

Para el año 2012, la población femenina del municipio de Popayán representa aproximadamente el $49 \%$ del total de la población, y el $51 \%$ restante lo conforma la población masculina. Lo anterior muestra que ningún sexo predomina sobre el otro, la población local está repartida entre ambos sexos.
Frente a la Población en Edad de Trabajar (PET), las tasas de crecimiento por sexo fueron mayores para el caso de los hombres que para las mujeres, siendo aproximadamente $6,21 \%$ y $5,45 \%$, respectivamente para la ciudad. En promedio, para los años de 2007 a 2013, de la población total de la ciudad que por su edad puede laborar, el $47 \%$ eran hombres y el $53 \%$ eran mujeres.

En cuanto a la Población Económicamente Activa (PEA) desagregada por sexo para Popayán desde 2007 a 2013 muestra que hay más hombres que mujeres trabajando o buscando trabajo en la ciudad, patrón que tendió a acentuarse a lo largo de los años, pues la tasa de crecimiento de la PEA para los hombres fue de $6 \%$ mientras que para las ellas fue del $1 \%$. Llama la atención, que a diferencia de la PET, en la que hay más mujeres en edad de trabajar en la ciudad, la PEA evidencia que son más los hombres los que efectivamente trabajan, y que hay más mujeres ingresando a la población inactiva. Esta brecha se puede explicar en razón a la discriminación laboral y a las fuertes barreras de acceso que ellas deben enfrentar en el mercado laboral, así como a los patrones culturales prevalecientes que las ubican fundamentalmente en el trabajo doméstico y reproductivo (Ilustración 1).

Ilustración 1. Población económicamente activa por sexo. Popayán, años 2007-20137

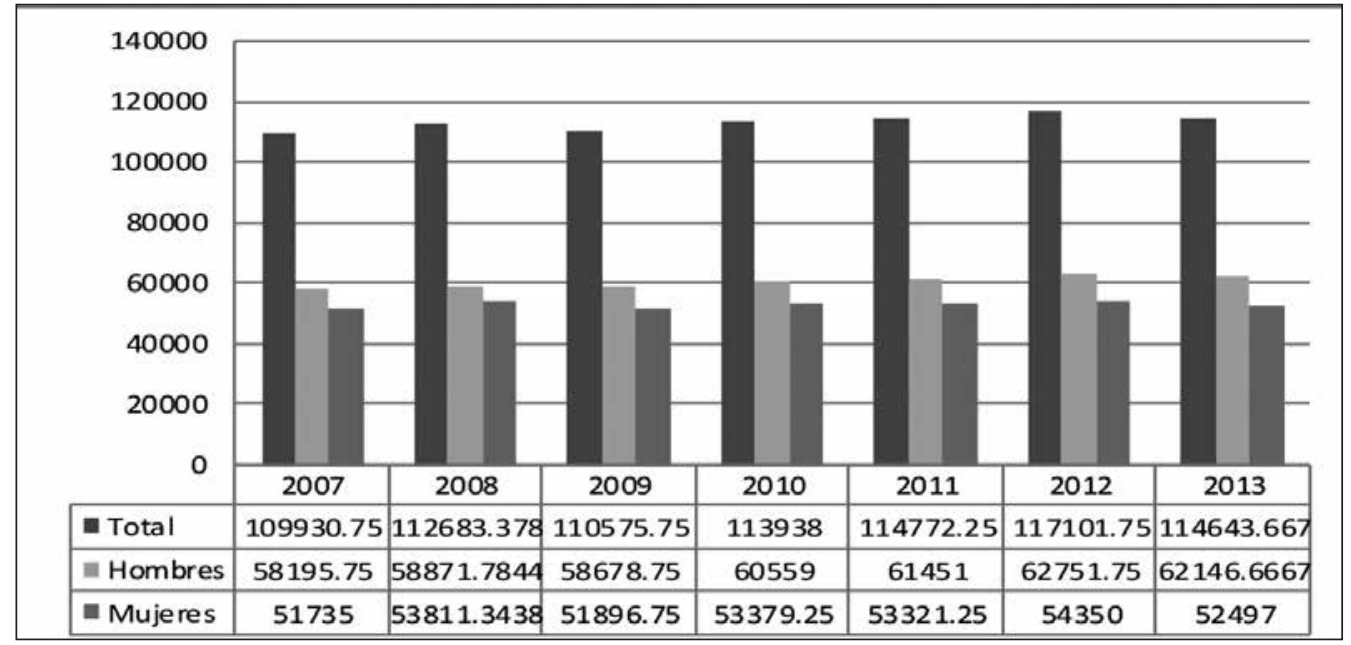

7 Fuente: Elaboración propia a partir de Departamento Administrativo Nacional de Estadística (DANE). 
La Tasa de Desempleo (TD) por sexo en Popayán fue en el periodo de referencia mayor para las mujeres $(21,6 \%)$ que para los hombres $(16,24 \%)$. Existe una tendencia decreciente en la tasa para ambos sexos, aunque tal disminución fue más marcada para los hombres que para ellas. Es decir, que de mantenerse este ritmo de descenso en la TD para ambos sexos, la brecha tendería a aumentarse en la ciudad de Popayán (Ilustración 2). A pesar de la tendencia levemente decreciente, la tasa de desempleo de Popayán se constituye en una tasa mucho mayor a la del promedio nacional, ubicando a la ciudad de manera frecuente en los primeros lugares de mayores niveles de desempleo en el país.

En términos etarios, la tasa de desempleo de las mujeres es mayor que la de los hombres para todos los rangos de edad. El desempleo más alto lo tienen las jóvenes (12 a 25 años de edad), con una tasa de desempleo promedio de $40 \%$ para todo el periodo, muy superior a la de los hombres de la misma edad que tienen $33,4 \%$ de desempleo. Las cifras evidencian que las jóvenes tienen mayores dificultades para in- gresar al mercado laboral contribuyendo a lo que la Organización Internacional del Trabajo (OIT) ha llamado una "generación perdida" de jóvenes que ha abandonado el mercado laboral tras haber perdido toda esperanza de trabajar y lograr una vida digna.

Desagregando el número de desempleados entre aquellos que tienen un desempleo abierto y oculto, se puede observar que este último es casi el triple en las mujeres del municipio de Popayán, es decir, hay muchas más mujeres que hombres en calidad de "trabajadores desalentados" en la ciudad. Lo anterior ratifica que las barreras de ingreso al mercado laboral son más fuertes para las mujeres de Popayán, lo que repercute en un menor interés de ellas en la búsqueda de trabajo. Los datos también se explican en razón que el trabajo reproductivo y doméstico que las mujeres realizan, hace que sea menor el tiempo dedicado a la búsqueda de empleo.

Como es de prever con todo lo anterior, la tasa de ocupación de los hombres es más alta que la de las mujeres para todo el periodo de análisis (llustración 3).

Ilustración 2. Tasa de desempleo por sexo. Popayán, años 2007-2013

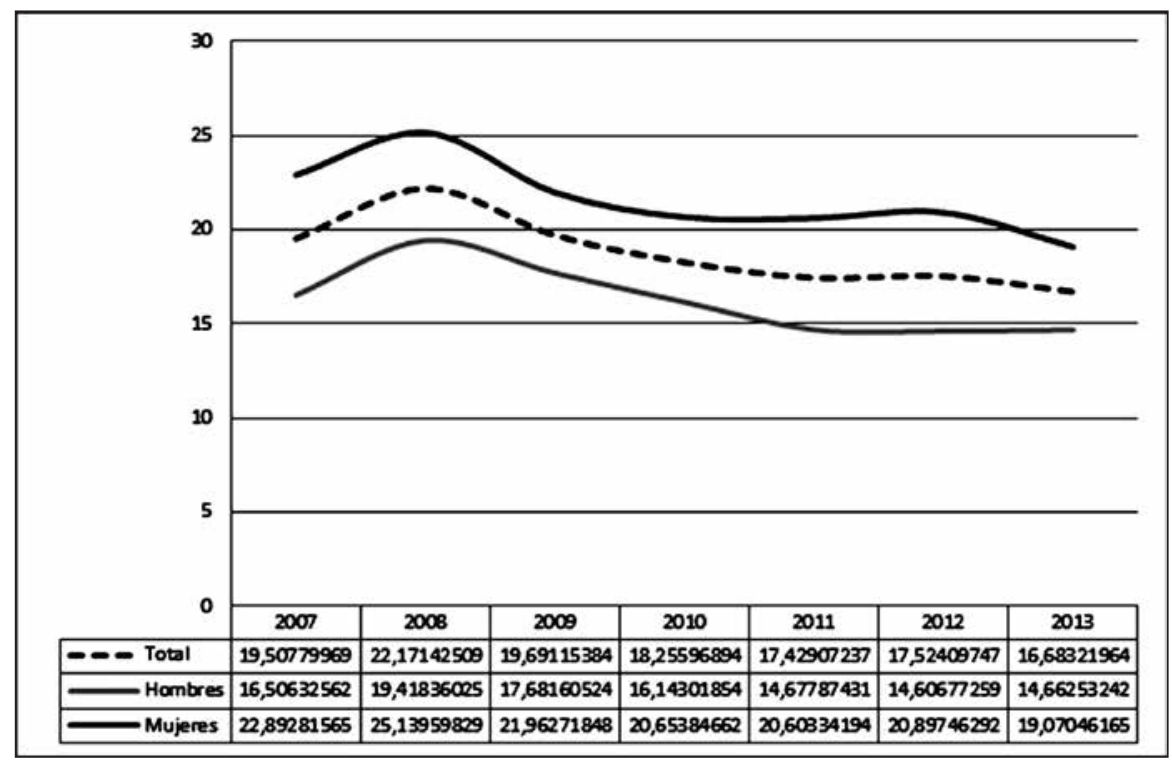

8 Fuente: Elaboración propia a partir de Departamento Administrativo Nacional de Estadística (DANE). 
Ilustración 3. Ocupados asalariados por sexo. Popayán, años 2007-201399

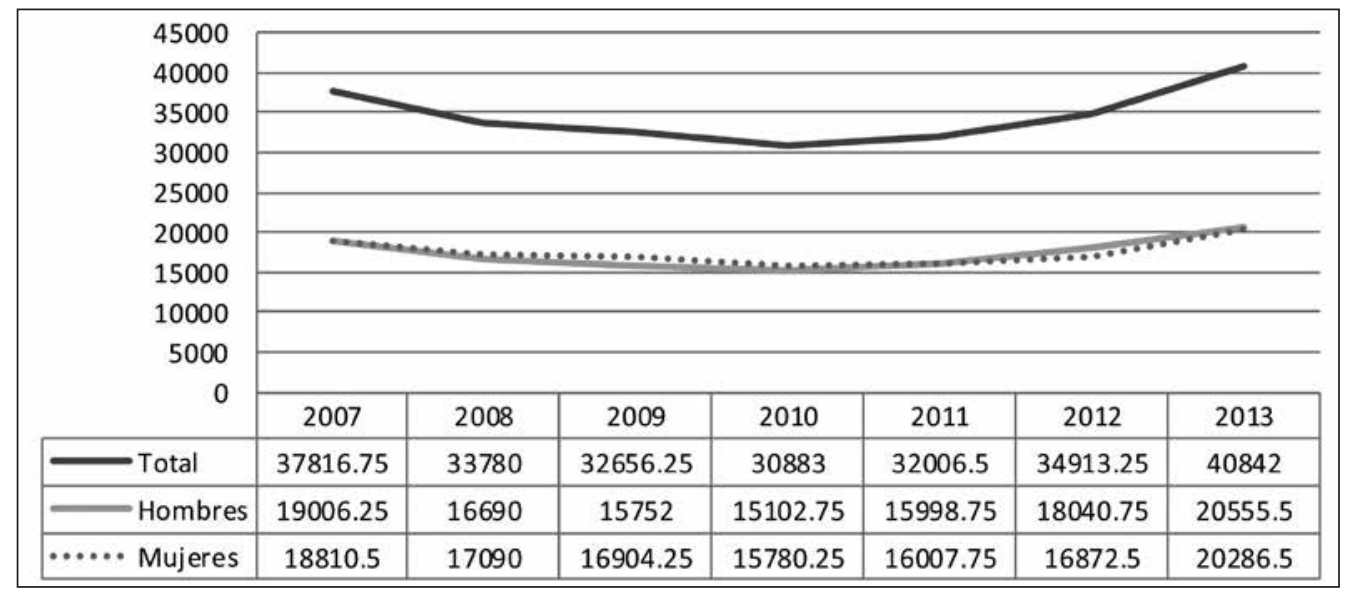

Se presenta muy poca variabilidad en la tasa de ocupación, lo que evidencia que la ciudad no es generadora de nuevos puestos de trabajo. En términos generales, cuando existe un crecimiento continuado de este indicador, se muestra que una sociedad supera los periodos de crisis económica y entra en fases de creación de empleo, por ello, la tendencia estable de este indicador en Popayán, hace pensar en los escasos niveles de crecimiento económico de la ciudad y su incapacidad para generar empleo. La mayor cantidad de ocupados de la ciudad está en la categoría de ocupados Independientes, seguido por los ocupados asalariados y finalmente los ocupados en Trabajo Sin Remuneración (TSR). Un análisis más detallado muestra cómo, en el periodo 2007-2013, en la categoría de ocupados independientes hay más hombres que mujeres, y se presenta un leve incremento de este tipo de ocupación en los periodos inmediatamente posteriores a la crisis económica de 2008 y 2009, coincidente con una disminución de los ocupados asalariados en el mismo periodo.

La categoría de ocupados independientes agrupa a los empresarios/as cuenta propia, lo que da cuenta de que en términos de empresarismo, los hombres las aventajan en la ciudad y la brecha no tiende a cerrarse. Podría pensarse que los procesos de acu- mulación de capital que dan origen a diversos emprendimientos, se encuentran fundamentalmente en manos de los varones, bien sea por la acumulación de excedente productivo, o por mayores facilidades para el endeudamiento, en cualquier caso, son ellos los que mayoritariamente hacen efectivo el trabajo independiente o por cuenta propia en la ciudad.

En contraste con lo anterior, la categoría de ocupados asalariados presentó muy poca diferencia entre ellos en la ciudad, tanto en términos de cantidad como de tasa de crecimiento. El trabajo asalariado, es un trabajo que por sus niveles de formalización, tiene menos condiciones de precariedad, y el hecho que no exista una brecha de género en este aspecto en la ciudad, se constituye en una buena circunstancia para las payanesas.

Las personas ocupadas sin remuneración en la ciudad de Popayán durante el periodo de análisis fueron principalmente mujeres. La cultura del "cuidado" hace que ellas desempeñen, en mayor medida que los hombres, actividades relacionadas con el bienestar comunitario, y el mismo trabajo doméstico que recae sobre ellas tanto en sus casas como en los espacios de la comunidad y que no tiene ningún tipo de remuneración. Mientras que en los hombres

\footnotetext{
9 Fuente: Elaboración propia a partir de Departamento Administrativo Nacional de Estadística (DANE).
} 
el indicador permanece estable a lo largo del periodo, en ellas tiene una mayor variabilidad con tendencia a aumentar, exceptuando el último año que hasta Septiembre no alcanza a superar los alcances anuales anteriores. En términos generales, las mujeres tienen mayor disposición a realizar trabajos no remunerados en el mercado que los hombres.

\subsection{Perfil de mujeres desempleadas y en situa- ción de pobreza en Popayán}

A partir de información institucional y el trabajo de campo realizado con 90 mujeres desempleadas y en situación de pobreza, se construyó un perfil que puede contribuir a identificar las necesidades y potencialidades de las mujeres para el trabajo en la ciudad de Popayán.

\subsubsection{Estructura socioeconómica}

Según Planeación Nacional, el 27,5\% de las familias del Cauca se encuentran en situación de extrema pobreza, y el $64 \%$ pertenece a los niveles I y II del Sisbén. Esta situación es coherente con las entrevistadas en el trabajo de campo, que viven en altas condiciones de precariedad económica, asociada a bajos niveles de escolaridad y bajos ingresos.

- Escolaridad: Los talleres focales evidencian que las mujeres en situación de pobreza y desempleo, comparten también un patrón de baja escolaridad. El $52,2 \%$ sólo tiene primaria, el $26,6 \%$ bachillerato, el $10 \%$ tiene un nivel técnico, el 7,7\% no tiene ningún nivel de escolaridad y sólo el 3,3\% alcanzó algún nivel de estudio universitario (Ilustración 4).

La mayor retención de la mujer de estratos altos en el sistema educativo reduce las presiones en la oferta de trabajo. Con su posterior inserción, los retornos no compensan la inversión realizada en educación. Es decir, un mayor nivel educativo no es garantía de obtener empleo e ingresos. Además, para alcanzar iguales niveles de ingreso que el de los hombres, ellas necesitan, comparativamente, por lo menos dos años más de educación. En los estratos bajos, altas tasas de desempleo en la población femenina vienen produciendo dos efectos de carácter estructural que refuerzan la dominación patriarcal: el retorno desde el sistema al trabajo doméstico no remunerado o la alternativa del trabajo sexual ${ }^{11}$.

Ilustración 4. Participantes en talleres focales por nivel de escolaridad alcanzado. Popayán, año $2013^{10}$

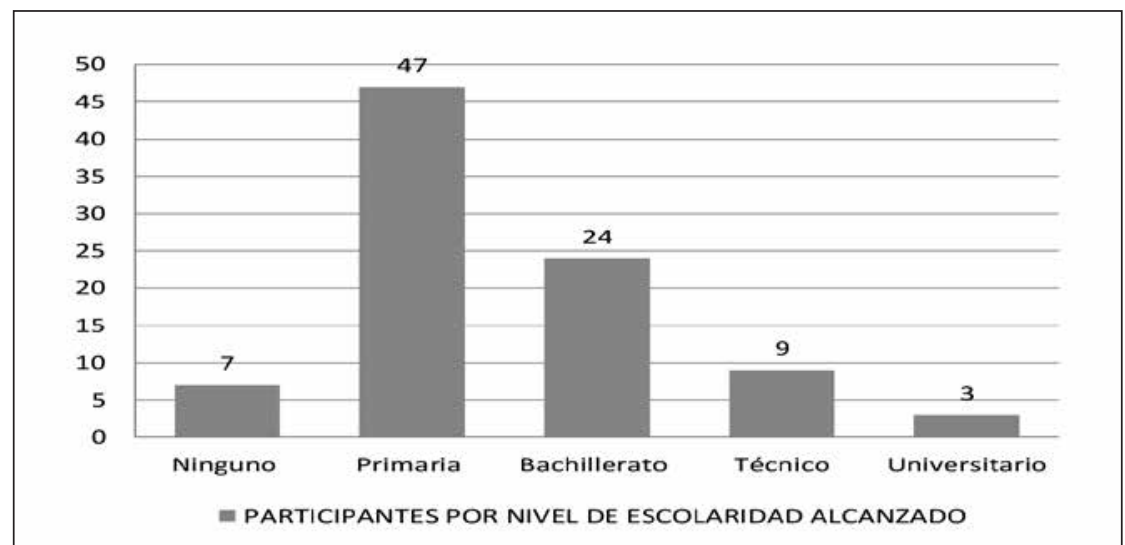

Fuente: Elaboración propia a partir de información obtenida en talleres focales.

11 Según datos de la Policía Nacional, el número de mujeres en trabajo sexual en Colombia se estima en cerca de 290.000. De otra parte, el tráfico internacional de mujeres colombianas ha crecido en los últimos 10 años. De acuerdo con la Comisión de Migraciones y Justicia de la Unión Europea existen medio millón de mujeres latinas en trabajo de prostitución en Europa, cuya procedencia mayoritariamente es de Brasil, Colombia y República Dominicana. Las trabajadora sexuales colombianas son mujeres jóvenes cuyas edades oscilan entre 15-35 años, la mayoría con bajo nivel de escolaridad, con hijos, han estado desempleadas por largos períodos, con problemas familiares y han sufrido de violencia intrafamiliar. 
Es necesario que desde el Estado se avance en una decisión política que garantice la educación formal para las mujeres en situación de pobreza en la ciudad de Popayán, pues las limitaciones en aspectos básicos de lectoescritura, operaciones matemáticas y demás, reducen notablemente las posibilidades de desarrollar habilidades para el trabajo que les permitan vincularse a sectores de mayores niveles de productividad, como lo veremos más adelante.

- Habilidades para el trabajo: Las habilidades que reportaron en los talleres focales se concentran fundamentalmente en los quehaceres domésticos (Ilustración 5). Conectado con lo anterior, el escaso nivel de formación no ha permitido que ellas desarrollen habilidades diferentes a las impuestas por el trabajo doméstico y reproductivo. La preparación de alimentos, la confección, la decoración, entre otras, son actividades que extienden el rol doméstico para ubicarlo en el escenario del mercado laboral. Vale decir, que las actividades en las cuales las mujeres participantes dicen tener habilidades, son actividades relacionadas con la percepción cultural existente sobre lo que las mujeres deben "saber hacer", que en general se reduce a los oficios domésticos, para los cuales han sido entrenadas desde tempranas edades. El origen campesino de muchas de las mujeres en situación de pobreza, participantes en los talleres, les otorga habilidades para las actividades agrícolas y se erige como un aspecto a tener en cuenta.

- Capacitación para el trabajo: De acuerdo con datos del Fondo para el Fomento del Empleo y la Protección al Desempleado (FONEDE) ${ }^{13}$, en la ciudad de Popayán 1483 hombres y 1399 mujeres desempleados/as recibieron capacitación para el trabajo desde

Ilustración 5. Participantes en talleres focales por categoría de habilidad. Popayán, año $2013^{12}$

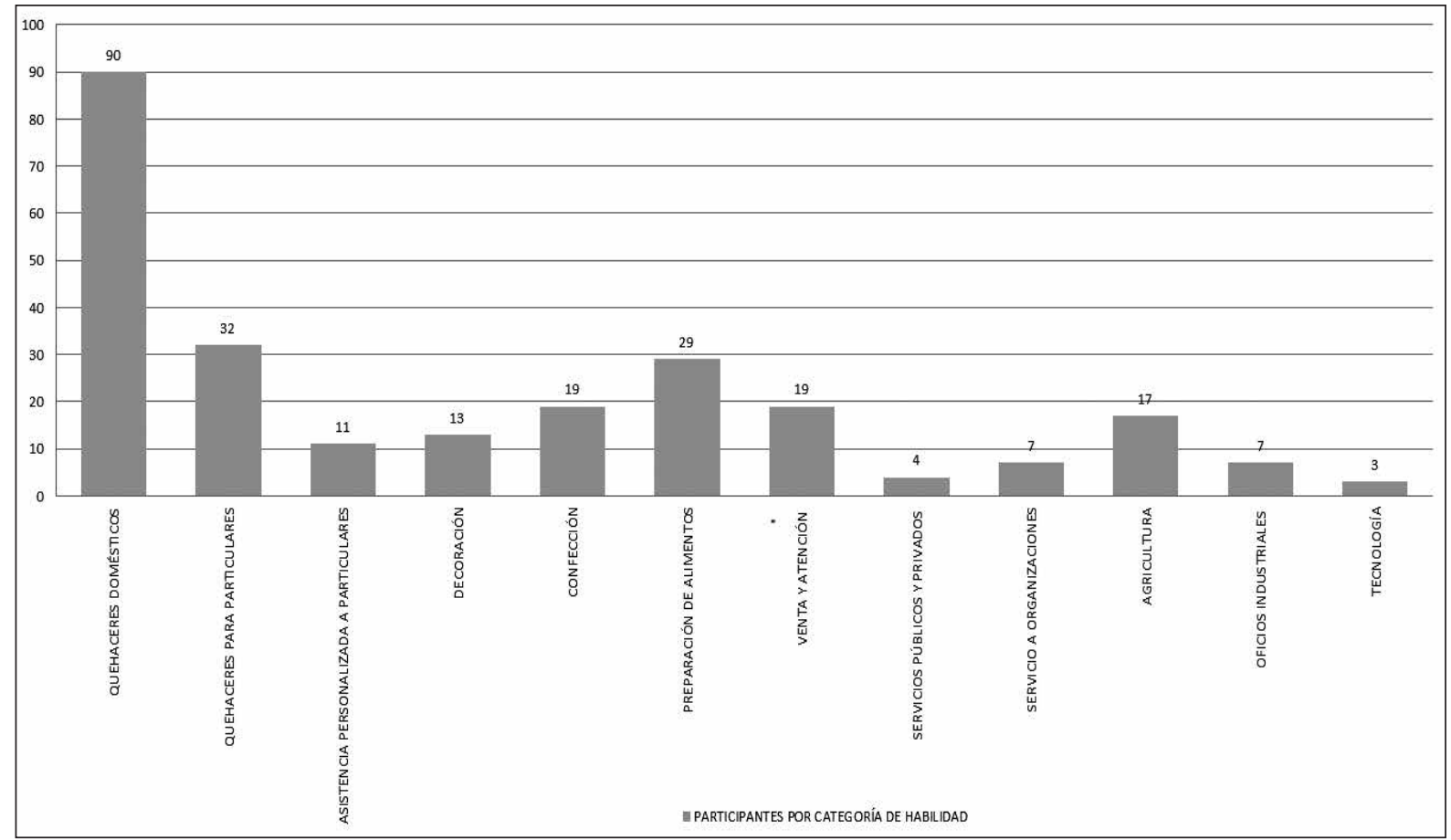

12 Fuente: Elaboración propia a partir de información obtenida en talleres focales.

13 Dicho fondo es administrado por las cajas de compensación familiar. 
el 2009 hasta marzo de 2013. El 52\% de las personas formadas en los cursos de capacitación fueron hombres y el $48 \%$ mujeres, lo que evidencia una brecha poco significativa en el acceso a este tipo de formación por parte de hombres y mujeres.

En términos de los cursos ofrecidos a las mujeres desempleadas para la obtención de mayores habilidades para el trabajo, el FONEDE reporta que en los años posteriores a la crisis económica (2009 y 2010), se incrementó el número de participantes de los procesos de capacitación para el trabajo ofrecidos por el FONEDE en la ciudad de Popayán. Es importante resaltar que desde la institucionalidad, representada en el Fondo FONEDE, prevalece un modelo cultural y tradicional de formación para el trabajo, en el que las mujeres son capacitadas para actividades relacionadas, en su mayoría, con una extensión del trabajo doméstico, centrada en actividades de bajos niveles de productividad e inserción tecnológica, como culinaria; belleza y peluquería; manicure y pedicure; manipulación de alimentos, decoración; ética y protocolo, etc. Sin embargo, desde el 2010 se ha incrementado la capacitación a ellas en manejo básico de sistemas e inglés, como actividades diferenciadoras de la oferta de cursos mencionada anteriormente.
Llama la atención que entre la oferta de capacitación para el trabajo ofertada por el FONEDE, el curso con mayor cantidad de mujeres participantes durante el 2009, fue el curso denominado "restaurando la unidad de la familia", así como se incluye cada año en la oferta principal de capacitación otros como "planificación familiar", "motivación para el encuentro familiar" o "resolución de conflictos"; esta circunstancia las centra nuevamente en el escenario de la familia como su eje principal y no se evidencia el aporte que se hace en términos formativos a su proceso de cualificación laboral.

En términos generales los cursos que se ofrecen a las mujeres desempleadas del municipio de Popayán están insertos en la lógica binaria que ubica las habilidades laborales de las mujeres en el escenario de los quehaceres domésticos y las deja por fuera de la capacitación en actividades que involucren aspectos técnicos y/o tecnológicos. Para el caso de los hombres, la oferta de capacitación para el trabajo está centrada en actividades que son generalmente más demandadas en el mercado, por ejemplo, cursos en energética smartflex, electricidad, mantenimiento y operación de montacargas, sistemas, soldadura básica, mecánica de motos, interpretación de planos, en-

Ilustración 6. Acumulado total de beneficiarios de cursos de capacitación según rangos de edad y género. Popayán, años 2009-2013 ${ }^{14}$

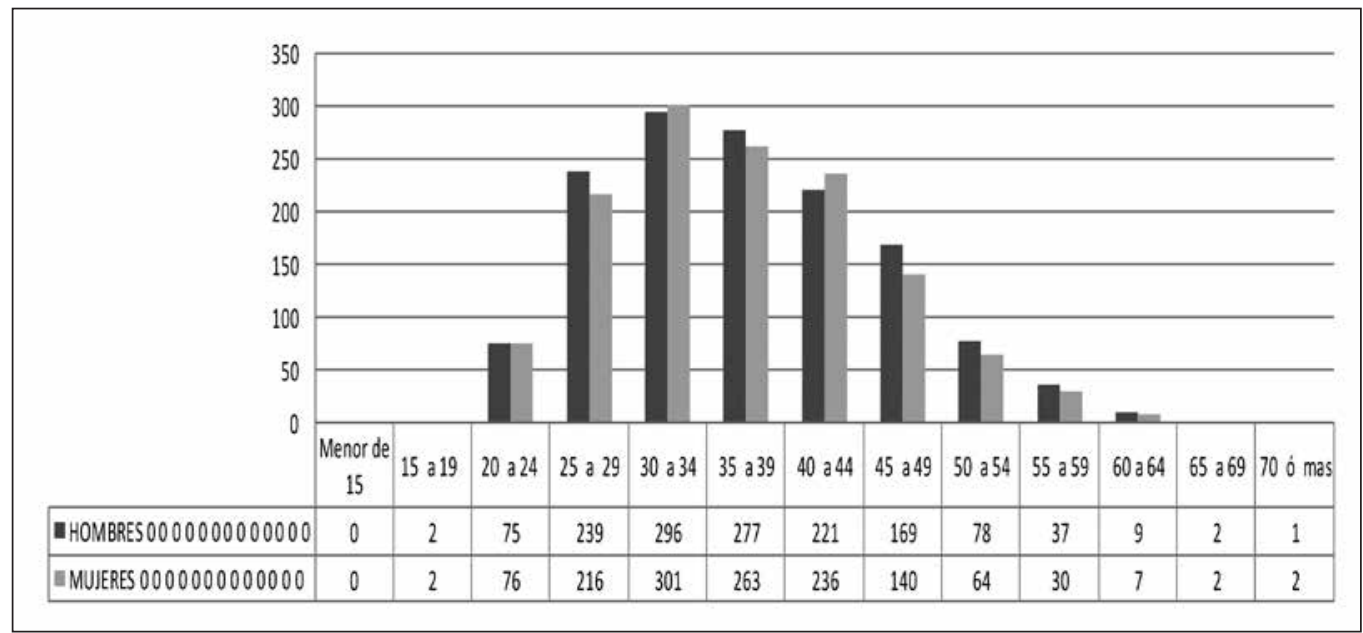

14 Fuente: Elaboración propia a partir de Fondo de Fomento al Empleo y Protección al Desempleado (FONEDE). 
tre otros. Esta información es plenamente coherente con lo expresado por ellas en los talleres focales.

Las mujeres desempleadas que más acuden a los procesos de capacitación para el trabajo en la ciudad de Popayán, están fundamentalmente entre los 25 y los 45 años de edad, lo que supone que las menores de 25 pueden encontrarse aún en el sistema educativo, y de otro lado, que el mercado inicia un proceso de "expulsión" de las mayores de 45 años, que desestimula la búsqueda y la capacitación (Ilustración 6). Este rango de edad es plenamente coincidente con el periodo de mayor dedicación al trabajo reproductivo.

Las desempleadas de estratos 1, 2 y 3 que acuden a los procesos de capacitación para el trabajo ofrecidos por FONEDE en la ciudad de Popayán, son principalmente bachilleres. Existe un mayor número de hombres desempleados que tienen nivel educativo de primaria y bachillerato, y hay mayor cantidad de mujeres desempleadas en los niveles educativos más altos como técnico y profesional (Ilustración 7). De esta manera se reitera lo mencionado anteriormente, en el sentido que no es suficiente tener más educación para que las mujeres efectivamente accedan al mercado laboral, a pesar de tener ellas mayores niveles educativos que los hombres, tienen mayores tasas de desempleo.

\subsubsection{Trabajo reproductivo y del cuidado}

Como se ha mencionado en la primera parte de este documento, el trabajo del cuidado de la vida que ellas realizan, generalmente sin ningún tipo de remuneración, es fundamental para el sostenimiento de la fuerza de trabajo, la socialización y educación de niños y niñas y en general para garantizar el funcionamiento de la sociedad. Por ello, no puede analizarse de manera aislada del trabajo de mercado, pues éste último se alimenta del primero.

El trabajo doméstico, que implica el cuidado a terceros, ha sido culturalmente asignado a las mujeres, y representa para ellas una carga laboral mayor que se traduce en una mayor cantidad de horas trabajadas. De acuerdo con la Encuesta nacional de uso del tiempo (ENUT) y la Cuenta satélite de economía del cuidado (valoración económica del trabajo de cuidados no remunerado) implementadas por el DANE ${ }^{16}$,

Ilustración 7. Acumulado total de beneficiarios de cursos de capacitación según grado de escolaridad alcanzado y género. Popayán, años 2009-2013 15

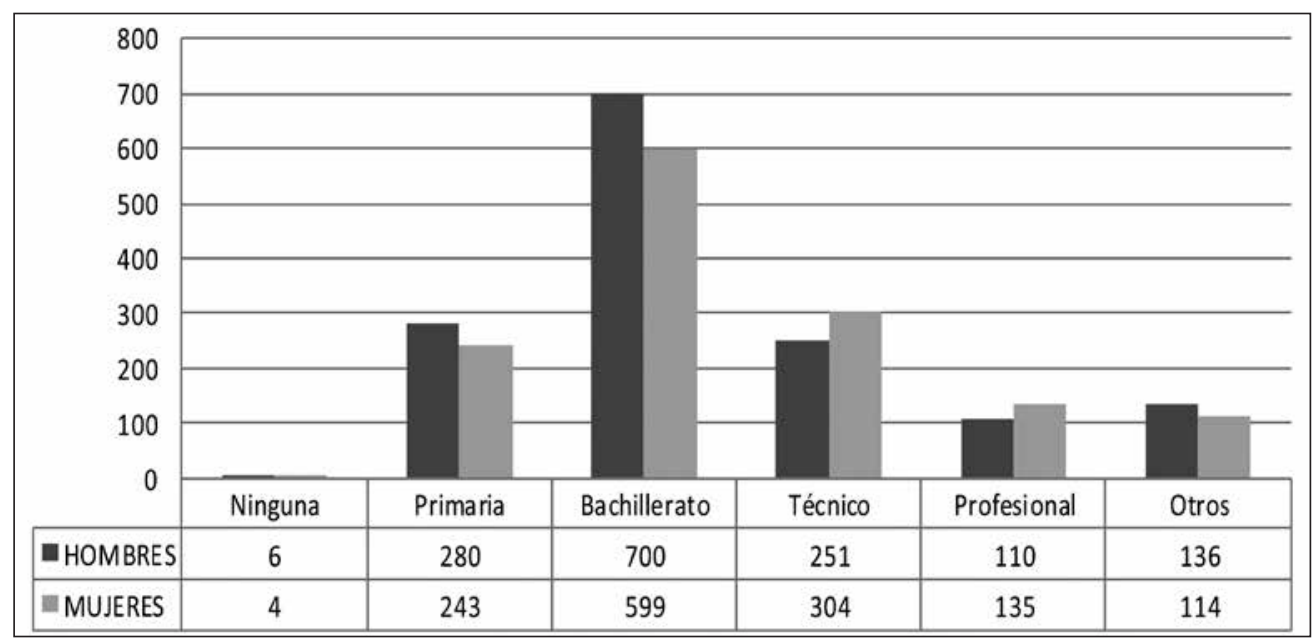

15 Fuente: Elaboración propia a partir de Fondo de Fomento al Empleo y Protección al Desempleado (FONEDE).

16 Implementada por el DANE en cumplimiento de la Ley 1413 del 11 de noviembre de 2010, conocida como la Ley de la Economía del Cuidado. 
en Colombia, en promedio ellas dedican tres veces más tiempo que los hombres a actividades de trabajo no remunerado, es decir, ellas realizan 6 horas diarias de trabajo no remunerado doméstico, mientras que los hombres sólo destinan dos horas diarias a esta labor. La cuenta satélite de economía del cuidado concluyó que la contribución del trabajo de cuidados no remunerado correspondería al 15,3\% del PIB de 2012 del cual el $4 \%$ lo aportan las mujeres.

Teniendo en cuenta lo anterior, y contrastándolo con las respuestas en los talleres focales, se puede aseverar que en la ciudad de Popayán, el trabajo doméstico tiene el mismo comportamiento que en el nivel nacional. Los talleres evidenciaron que las mujeres no tienen plena conciencia de lo que significa el trabajo doméstico, del cuidado y reproductivo y su aporte social. Lo consideran como algo "natural" por el hecho de ser mujeres. Culturalmente, sus madres les transmitieron la importancia de aprender el trabajo doméstico desde niñas como aspecto fundamental para su desenvolvimiento como mujer adulta, ama de casa y madre, por ello consideran que sus mayores habilidades para el trabajo se concentran en los oficios domésticos.

De acuerdo con sus intervenciones, el trabajo doméstico recae principalmente en las mujeres, son ellas las que realizan todas las labores de crianza, limpieza y cuidado de sus familias. La dedicación casi exclusiva a estas actividades muestra que no existe una distribución de dedicación del tiempo al trabajo doméstico con sus parejas o con el resto de la familia. Mencionan que sólo las hijas, otras mujeres, son las que las apoyan en algunas de las actividades descritas.

La dedicación de un promedio de 15 horas a estas labores, les impide participar en otros procesos de formación para el trabajo, capacitaciones, o la misma búsqueda de empleo. Sin embargo expresan que si pudieran trabajar en el mercado laboral, estarían dispuestas a hacerlo. Esta situación es compatible con la mayor incidencia en las mujeres del desempleo oculto en la ciudad de Popayán. El excesivo tiempo de dedicación al trabajo doméstico y reproductivo se contrapone al escaso tiempo que dedican al descanso y al ocio. En los testimonios se evidencia que al no ser reconocido como un trabajo, las actividades domésticas no tienen horarios de reposo, generando en las mujeres un agotamiento estructural, que en el largo plazo se expresa en enfermedades, envejecimiento prematuro, etc.

Es urgente que desde la institucionalidad pública, se tomen medidas que permitan promover un debate social, público y político en Popayán sobre el aporte del trabajo reproductivo que hacen ellas a la sociedad y a la economía, así como la necesidad de transformar la dedicación del uso del tiempo entre hombres y mujeres al trabajo doméstico y del cuidado. Una negociación más equitativa con las parejas, en términos de la dedicación de cada uno a la crianza y el cuidado, permitirá a las mujeres en situación de pobreza dedicar tiempo a su formación para el trabajo o a otras actividades importantes para su participación como ciudadanas plenas de derechos en la sociedad.

\subsubsection{Causas y efectos del desempleo en la vida de las mujeres}

Las participantes en los talleres focales no dudan en ubicar la discriminación por el hecho de ser mujeres, como una de las razones principales de su situación de desempleo, pero también reconocen otros obstáculos. La maternidad y la dedicación al trabajo reproductivo es un impedimento reiterado, pues expresan que sólo ellas asumen este tipo de actividades y no encuentran apoyo ni en sus parejas ni en el Estado, para que se faciliten las condiciones del cuidado de los hijos(as) y de esta manera se facilite igualmente su búsqueda y/o retención de algún empleo obtenido.

Ellas identificaron su escasa capacitación a nivel formal e informal como uno de los grandes impedimentos para conseguir empleo. Como se mencionó anteriormente, un alto porcentaje de las participantes solo contaba con estudios de primaria, y sus habilidades para el trabajo estaban concentradas en la extensión de las actividades domésticas en el mercado laboral. A diferencia de los hombres, muchas de ellas expresan que deben "pedir permiso" a sus esposos para buscar un empleo. El machismo expresado en los celos y la desconfianza, son una manifestación de 
lo incómodo que resulta en sus parejas la independencia económica y la autonomía, convirtiéndose en un obstáculo contundente a la hora de buscar o conseguir un empleo.

La edad es un factor que algunas de ellas identificaron como un obstáculo. Las más jóvenes, expresaron las dificultades que la "falta de experiencia" acarrea a la hora de buscar empleo y las mayores de 40 años expresaron que el mercado ya las "considera viejas" para muchas actividades (especialmente en el tema de ventas, donde la juventud, la presentación personal y ciertas normas de apariencia física, son importantes en el proceso de enganche).

Finalmente, la enorme dificultad de acceso al crédito es un aspecto que identifican como obstáculo para el emprendimiento. La inexistencia de bienes raíces a su nombre (bien sea por su condición económica o porque los propietarios son sus esposos) no les permite respaldar una deuda con alguna entidad financiera para la ejecución de algún proyecto productivo. Los impactos que el desempleo causa en las mujeres son múltiples y pasan por aspectos de orden físico y emocional. La ruptura de las relaciones armónicas en el hogar es uno de los efectos más mencionados, reflejado en peleas y discusiones con la pareja, con los hijos, etc. Los sentimientos de impotencia, frustración y tristeza, tienen impactos emocionales en ellas y sus familias, que repercuten de manera contundente en su salud. Un amplio número de participantes refirió dolores de cabeza, de espalda, presión alta, insomnio, como efecto de las condiciones de pobreza y precariedad que trae consigo el desempleo. Otros aspectos mencionados como la desnutrición de los hijos y las hijas y la imposibilidad de brindarles educación, tienen efectos de largo plazo que contribuyen a mantener el círculo de pobreza.

\section{Participación de las mujeres en el mercado laboral de la ciudad de Popayán: múltiples análisis econométricos}

El municipio de Popayán tiene un desempleo que se caracteriza por ser uno de los más elevados a ni- vel nacional (alrededor del 18\%), afectando primordialmente a las personas jóvenes. El indicador por género que existe sobre desempleo, muestra que a nivel local las mujeres siempre están liderando las cifras más elevadas. Es decir, la poca demanda de trabajadores existente, es copada generalmente por hombres. A priori podría justificarse éste elevado desempleo por un déficit de demanda de trabajo, sin embargo la tasa de desempleo depende también de la oferta laboral, es decir, del número de personas en edad de trabajar que están dispuestas a participar en el mercado mediante la búsqueda o el ejercicio de una ocupación remunerada así como de la disposición a trabajar más o menos horas por parte de quienes pertenecen o podrían pertenecer a la población laboral.

El presente estudio analiza la evolución de la participación laboral de las mujeres en la ciudad de Popayán, aunque se reconoce que la Tasa Global de Participación (TGP) responde a determinantes de largo y corto plazo, el análisis se limitará a los determinantes de corto plazo, dado que la información suministrada por el Departamento Administrativo Nacional de Estadística (DANE) correspondiente al municipio, solo está disponible desde el primer trimestre de 2007, período en el cual Popayán se incluye en la Gran Encuesta Integrada de Hogares (GEIH).

\subsection{Caracterización de la participación femenina en el mercado laboral de la ciudad de Popayán}

De acuerdo con lo establecido anteriormente, en el municipio de Popayán la participación femenina en el mercado laboral es inferior a la participación masculina. En la brecha entre la participación laboral de hombres y mujeres, han repercutido diferentes factores, entre los culturales y sociales se encuentran la dificultad en la disposición y acceso históricos de las mujeres al mercado laboral, al levantarse como barreras interiorizadas por sí mismas y por la sociedad relacionadas con su responsabilidad asimétrica del cuidado del hogar, a pesar de ello, se reconoce que la participación femenina desde el inicio hasta el final del periodo ha presentado un crecimiento levemente superior al masculino en promedio desde 
2007 a 2013 y cerrando igualmente en el último trimestre (Ilustración $10^{17}$ ).

Esto indica que en el mercado laboral del municipio, aunque siga siendo mayor la participación de los hombres que de las mujeres, en algunos periodos han sido ellas quienes han buscado insertarse activamente y tal presión ha sido más marcada que la masculina en los últimos años. Aunque esto se explica en parte al logro de ciertas vindicaciones, también tiene una alta asociación a factores externos, muchas veces coyunturales, que las obligan a hacerlo por su responsabilidad con el hogar. Uno de esos factores externos es la necesidad de mayores ingresos monetarios dentro del hogar, relacionada directamente con las crecientes dificultades afrontadas por los hogares que flaquean en medio de las diversas crisis económicas de la última década con sus implicaciones directas en la desocupación u ocupación inestable a lo largo y ancho del mundo. Inestabilidad laboral a la que se suma la precariedad de las economías neoliberales y el aumento de la pobreza desde hace varias décadas.

Es así como por un lado, las mujeres se han visto en la necesidad de buscar por sí mismas una fuente de ingresos adicional a la del jefe de hogar quien se asume como el aportante principal de ingresos o el único en muchos hogares, por el que en momentos de crisis se afligen los ingresos del hogar (vía desocupación o contratación inestable del jefe); por otro lado, la tendencia en los últimos tiempos en términos de la jefatura de los hogares por sexo indica que han asumido un papel como jefes de hogar de manera creciente ya sea por disolución de parejas o por el creciente número de madres solteras desde el embarazo registrado sobre todo en los países subdesarrollados, llevándolas a buscar ingresos para solventar los gastos de las personas a su cargo; esto según Velásquez (2010) se ha reflejado en Colombia con el crecimiento de un $5 \%$ del fenómeno de jefatura femenina en los hogares a lo largo del periodo inter-censal 1993-2005.
Todo ello ha llevado a que cada vez más mujeres, de todas las condiciones sociales y económicas, asuman el rol de proveedoras principales de sus hogares y sean reconocidas por los demás miembros como tales, acrecentándose la participación laboral femenina aunque con niveles de ingreso en general inferiores a los de los hombres y por tanto reportando en sus hogares condiciones de vida distintas a las de aquellos con posibilidad de aporte económico por parte de miembros secundarios. Según la misma autora, son esos hogares que acarrean con mayor vulnerabilidad en tanto hay una sola proveedora en el hogar y con ello mayor dependencia económica ahondada por la condición de género que le desfavorece con menores ingresos comparativos.

Analizando el ciclo de la Tasa Global de Participación Femenina (TGPF) para el período trimestral entre 2007 y 2013 (Ilustración 11 ${ }^{18}$ ) es claro que el comportamiento de este indicador puede explicarse en cuatro períodos diferenciados, el primero durante el 2007-1 hasta el 2008-2, presentando un comportamiento ascendente y llegando hasta su nivel más alto durante el período de análisis, otro tramo de análisis se puede identificar a partir de 2008-3 hasta el 2009-2, se presenta una fuerte caída en la tasa de participación femenina. Entre el 2009-3 y 2013-1 la TGPF en el municipio se mantuvo estable, oscilando alrededor del $52 \%$. Finalmente, a partir de este período hasta la actualidad el indicador ha descendido significativamente hasta niveles por debajo del $49 \%$. Para explicar este comportamiento se afirma, en Santamaría \& Rojas (2001), que en el corto plazo la incorporación de la mujer y los demás miembros secundarios de las familias está marcada por el desempeño de la economía. Cuando el crecimiento de la economía ha generado incrementos en los ingresos de los hogares, el aumento de la participación laboral es consistente con un escenario en que las oportunidades aparecidas en el mercado han alentado a muchas personas que se encontraban inactivas (es lo que la teoría denomina fenómeno del trabajador alentado). En momentos en que dichos ingresos se han reducido, el incremento

\footnotetext{
17 Ver Anexos.

18 Ver Anexos.
} 
de la participación laboral de algunos miembros del hogar se da para compensar esta pérdida de ingresos (trabajador adicional). Estas hipótesis serán validadas en el siguiente apartado.

\subsection{Hipótesis de la trabajadora adicional en el mercado laboral de las mujeres en la ciudad de Popayán}

La participación laboral de las mujeres en Popayán, medido a partir de la TGP femenina en el mercado de trabajo local, se puede explicar a partir del comportamiento del nivel de actividad económica experimentado en el mismo municipio. Para tal fin, y debido a la ausencia de estimación para el Producto Interno Bruto del municipio de Popayán, fue necesario utilizar como variable proxy el consumo de energía en la ciudad. Lo anterior se justifica porque un componente esencial del crecimiento, desde la Revolución Industrial, ha sido el uso intensivo de la energía. ${ }^{19}$ La información del consumo de ener- gía eléctrica mensual en el municipio de Popayán se obtuvo a partir de la Compañía Energética del Cauca (CEDELCA) desde el año 2006 hasta agosto de 2010, y desde septiembre de 2010 hasta 2013 la información fue suministrada por la Compañía Energética de Occidente $(\mathrm{CEO})^{20}$.

En la Ilustración 8 se relaciona la dinámica del comportamiento energético de la ciudad con el PIB del Cauca, concluyéndose que en el período comprendido entre 2007 y 2013 la economía departamental y la municipal podrían considerarse procíclicas. ${ }^{21}$ Adicionalmente, también se puede inferir un leve rezago entre las variables, es decir que el comportamiento del PIB del Cauca podría estar anticipado por la dinámica económica de su capital, durante un período inmediatamente anterior. Además, la Ilustración 8 se muestra el elevado grado de relación entre la variación del PIB departamental y la variación del consumo de energía, como variable proxy del nivel de actividad económica del municipio.

Ilustración 8. Ciclo del PIB Cauca y del nivel de actividad económica en Popayán. Filtro de Hodrick-Prescott, periodo 2007-1 - 2013-322

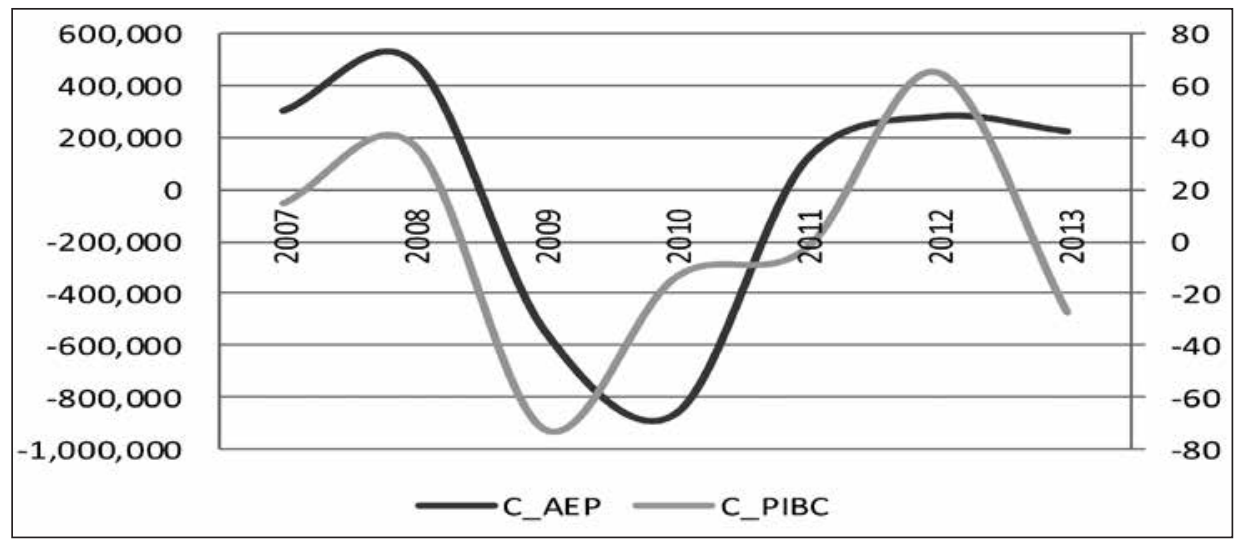

19 Siguiendo a Squalli (2007), Ozturk (2010) y Magazzino (2011), se utiliza la hipótesis de retroalimentación entre el consumo de energía eléctrica y el PIB, es decir, existencia de causalidad bi-direccional, del consumo de energía eléctrica al PIB, y del PIB al consumo de energía eléctrica. Esta última hipótesis es la que se acoge en la presente investigación, sustentado en los resultados obtenidos por Campo \& Sarmiento (2011), quienes concluyen que para Colombia se acepta la hipótesis de retroalimentación, sugiriendo una interrelación y complementariedad entre el consumo de energía eléctrica y el PIB, esto es, existe una relación de causalidad bidireccional.

20 Con el fin de establecer las comparaciones entre distintas series, fue necesario contar con una serie libre de oscilaciones estacionales, para ello se utilizó la metodología simple de medias móviles en modo multiplicativo, dada la naturaleza de la serie.

21 En términos técnicos se mide con la correlación estadistica que existe entre ellas. Un signo positivo evidencia comportamientos pro cíclicos, un signo negativo contra cíclicos, y cero que no guardan ningún tipo de relación. Para este caso, el coeficiente de correlación entre las variables fue de 0,63 .

22 Fuente: Elaboración propia. C_AEP: Ciclo de la actividad económica en Popayán; C_PIBC: Ciclo del PIB del Cauca. 
La teoría económica neoclásica ha abordado la decisión individual de trabajar o no a partir de la resolución del problema de maximización de la utilidad de determinado individuo, en la que los insumos son la renta y el ocio, ambos relacionados directamente con el trabajo. De esta forma, la persona en cuestión estará dispuesta a ofrecer una cantidad de trabajo, sólo si la utilidad que obtendría por el ingreso percibido al menos compensa la pérdida por el menor ocio. El efecto total que un aumento del ingreso tiene sobre las decisiones de participar se puede clasificar en dos componentes. El primero es el efecto ingreso, que disminuye la oferta de trabajo debido al aumento del ocio demandado por el mejoramiento en las condiciones de vida. El otro es el de sustitución que aumenta la oferta, pues se encarece el costo de oportunidad del ocio por los mayores ingresos (el individuo sustituye ocio por más trabajo).

La presencia de ambos efectos actuando en direcciones opuestas en algunos casos crea ambigüedad en las predicciones sobre la oferta laboral. El resultado final dependerá de cuál de los dos efectos es mayor. Dado que la condición de cada miembro familiar al interior del hogar y en el mercado laboral afecta las decisiones de los demás integrantes, los modelos individuales se han sofisticado para tratar de explicar las decisiones de las personas dentro de un contexto familiar. La contribución adicional de ésta perspectiva es analizar el comportamiento en términos de participación laboral de los miembros secundarios (esposas, hijos e hijas solteros), los cuales determinan las variaciones de la oferta en el corto plazo (Santamaría \& Rojas, 2001).

A partir de la siguiente ecuación:

$$
T P S=a+b W_{s}+c W_{p}+\varepsilon(1)
$$

En donde TPS es la tasa de participación laboral de los miembros secundarios del hogar (los que generalmente no trabajan); $W_{s}$ es el salario de los miembros secundarios del hogar; $W_{p}$ es el salario del miembro principal del hogar; $a, b$ y $c$ son los parámetros de ajuste; $\varepsilon$ son los errores aleatorios. Enmarcados en un análisis de corto plazo, con el fin de analizar la oferta laboral de las mujeres en el municipio de Popayán, suponiendo que en la ecuación 1 las variaciones de y cambian en la misma proporción, se pueden presentar cuatro posibles respuestas de la oferta laboral femenina, lo cual se puede apreciar en la Tabla 1.

Tabla 1. Ciclo económico, dinámica salarial y tasa de participación laboral del trabajador secundario del hogar ${ }^{23}$

\begin{tabular}{|c|c|c|c|c|}
\hline $\begin{array}{c}\text { Ciclo } \\
\text { Económico }\end{array}$ & $\begin{array}{c}\text { Dinámica } \\
\text { Salarial }\end{array}$ & Parámetros & $\begin{array}{c}\text { Respuesta } \\
\text { de la TPS }\end{array}$ & Hipótesis \\
\hline Auge & Suben & $|\mathrm{b}|>|\mathrm{c}|$ & Aumenta & $\begin{array}{c}\text { Trabajador } \\
\text { alentado }\end{array}$ \\
\hline Auge & Suben & $|\mathrm{b}|<|\mathrm{c}|$ & Disminuye & $\begin{array}{c}\text { Trabajador } \\
\text { excedente }\end{array}$ \\
\hline Crisis & Caen & $|\mathrm{b}|>|\mathrm{c}|$ & Disminuye & $\begin{array}{c}\text { Trabajador } \\
\text { desalentado }\end{array}$ \\
\hline Crisis & Caen & $|\mathrm{b}|<|\mathrm{c}|$ & Aumenta & $\begin{array}{c}\text { Trabajador } \\
\text { adicional }\end{array}$ \\
\hline
\end{tabular}

Según Osorio (1997), la hipótesis del trabajador adicional se presenta cuando en una situación de recesión, resultado de la reducción de las horas trabajadas o del desempleo total del jefe de hogar, hace que trabajadores secundarios o "adicionales" se incorporen a la búsqueda de empleo, con el fin de restaurar los ingresos familiares y mantener los patrones de consumo. La hipótesis del trabajador desalentado ocurre cuando en una situación de recesión prolongada en donde las oportunidades de trabajo permanecen escasas, un buen número de trabajadores secundarios que no han podido encontrar empleo, terminan por retirarse de la fuerza de trabajo. La hipótesis del trabajador alentado corresponde a una situación de auge económico, en la que una subida de los salarios conduce a que se incremente la participación laboral de los trabajadores secundarios.

Finalmente, la hipótesis del trabajador excedente se presenta en un período de auge económico, cuando un alza en el nivel de salarios puede conducir a que disminuye la participación laboral de los trabajadores secundarios. Dado que no es posible inferir

23 Fuente: Osorio (1997). TPS: Tasa de participación laboral del trabajador(a) secundario. 
a priori sobre el comportamiento de la oferta laboral de las mujeres payanesas ante las variaciones en el ciclo económico y los salarios, a continuación se presentan los resultados de la modelación econométrica para lograr comprender la dinámica de la participación laboral femenina en la ciudad de Popayán. Inicialmente, asumiendo que la mayoría de jefes de hogar son hombres, ${ }^{24}$ se puede relacionar la TGP femenina con la Tasa de Desempleo (TD) masculina, con el fin probar la hipótesis de la trabajadora adicional (Ilustración 1225).

Las cifras muestran que entre el 2007-1 y 2008-1, cuando el comportamiento de la TD masculina fue decreciente, la TGP femenina crece considerablemente, mostrando una relación inversa entre estos indicadores, asociada a un coeficiente de correlación para este período de -0,309. Podría afirmarse que el alza en el nivel de ingresos de las familias payanesas, debido a la mayor ocupación masculina, incentiva la entrada de fuerza laboral femenina, sugiriendo la validación de la hipótesis de la trabajadora alentada. Sin embargo, posterior a este período la dinámica cambia considerablemente, entre los trimestres comprendidos entre 2008-2 y el 2013-3, la relación es directa indicando que ambas variables se movieron en la misma dirección. Al comienzo de este período se presentan las tasas de desocupación más elevadas en los hombres, oscilando alrededor del 20\%; el coeficiente de correlación durante 2008-2 y 2009-2 (niveles más altos de desempleo en los hombres) entre las variables fue de 0,649 , mientras que durante 2009-3 y 2012-4 (niveles más bajos de desempleo masculino) el coeficiente bajó un poco, pero se mantuvo alrededor del 0,60. Para terminar, en el período 2013-1 el desempleo en los hombres aumenta considerablemente (16,8\%), lo cual también presiona el alza en la TGP de las payanesas, incluso la correlación aumenta hasta 0,834 , validando la hipótesis de la trabajadora adicional.

En síntesis, para todo el período de análisis el coeficiente de correlación entre la TD masculina y la TGP femenina en la ciudad de Popayán fue de 0,366, se evidencia así el efecto de la trabajadora adicional en los hogares payaneses, resaltando que durante el 2008 y 2012, la TD de los hombres sufre un período de estancamiento, y por tal motivo cuando ésta aumenta un poco la respuesta de la TGP de las mujeres es más que proporcional, corroborando el carácter estabilizador que tiene la participación femenina en los ingresos del hogar, sobre todo en momentos de crisis. Adicionalmente, se puede relacionar la dinámica del nivel de Actividad Económica de Popayán (AEP) y la tasa de participación femenina (TGPF) en la ciudad de Popayán. En períodos de crisis económica, asociados a un comportamiento descendiente de la actividad económica de Popayán, construida como proxy del crecimiento económico de la ciudad, la TGP femenina tiende a aumentar (Ilustración $13^{26}$ ).

En la mayoría de períodos existe una relación inversa entre la variación del nivel de actividad económica (LAEP) y la variación de la tasa global de participación femenina (LTGPF) de la ciudad de Popayán, sin embargo cuando la variación de la actividad económica en la ciudad se rezaga dos períodos, el nivel de relación entre ambas variables aumenta considerablemente, aunque se mantiene la relación inversa. Lo anterior indica que el efecto del nivel de actividad económica experimentado en el municipio, aproximadamente 6 meses atrás, podría determinar la decisión actual de las payanesas de participar en el mercado laboral.

Al relacionar el crecimiento económico, rezagado en dos períodos trimestrales y la variación de la participación femenina (TGPF) en Popayán, se pueden identificar tres etapas, correspondientes a puntos de corte de las dos curvas. La participación laboral femenina entre 2007-1 y 2009-2 presentó una correlación negativa con respecto a la variación del nivel de actividad económica rezagada, entre 2009-3 y 2011-1 la correlación fue positiva y finalmente desde el 2011-2 hasta el 2013-3 la relación entre ambas

\footnotetext{
24 Según información del DANE a partir del Censo de 2005, para Popayán la jefatura de los hogares corresponde aproximadamente un $67 \%$ a los hombres, y $33 \%$ restante a las mujeres.

25 Ver Anexos.

26 Ver Anexos.
} 
variables se tornó nuevamente negativa. Este resultado implica que para todo el período la correlación fue negativa $(-0,4676)$, es decir que la variación de la TGP femenina y la AEP, con dos períodos rezagados, es inversa, cuando el crecimiento económico de la ciudad es relativamente bajo, ellas deciden participar en el mercado laboral local con mayor fuerza. El fenómeno de la trabajadora adicional, por tanto, se acentúa en épocas de crisis económicas. De otro lado, incluyendo en el análisis el comportamiento de la Tasa Global de Participación Masculina (TGPM), con el fin de establecer cuál de las dos variables de participación laboral en el mercado laboral, por sexo, se ve más afectada por el nivel de actividad económica en la ciudad de Popayán, se puede observar la Ilustración 9.

De igual forma se puede evidenciar que, para todo el período de análisis, la TGPF tiene una reacción más pronunciada ante la variación del nivel de actividad económica local (con un rezago de dos períodos), en comparación con la TGPM, lo anterior no sugiere que la participación laboral masculina no esté explicada por el comportamiento de la economía payanesa, sino que su comportamiento es más estable si se compara con la decisión de las mujeres de participar o no en el mercado laboral, debido al papel que tradicionalmente el hombre cumple como jefe del hogar y la mujer como trabajadora secundaria.

La relación entre la variación de la TGPF y la TGPM, ratifica que la tendencia entre ambas tasas globales de participación laboral es similar y se relacionan directamente. Analizando ésta relación por tramos, se observa que en períodos de crisis económica, como la presentada entre 2008-1 y 2010-1, la relación entre ambas variables se fortalece aún más.

Adicionalmente, si se compara el efecto del nivel de actividad económica en cada una los resultados sugieren que en un período de crisis económica, el impacto que tiene la dinámica económica en la decisión de participar o no en el mercado laboral tanto de hombres como mujeres, es bastante similar. Sin embargo, cuando se analiza ésta relación en períodos posteriores a un auge económico, como el presentado a partir de 2010-2, la relación entre ambas variables se debilita $(0,5957)$. De igual forma, si se compara el efecto del nivel de actividad económica en cada participación laboral, para este período, se

Ilustración 9. Variación del nivel de actividad económica, tasa global de participación femenina y masculina en Popayán (dos rezagos). Periodo 2007-1 - 2013-327

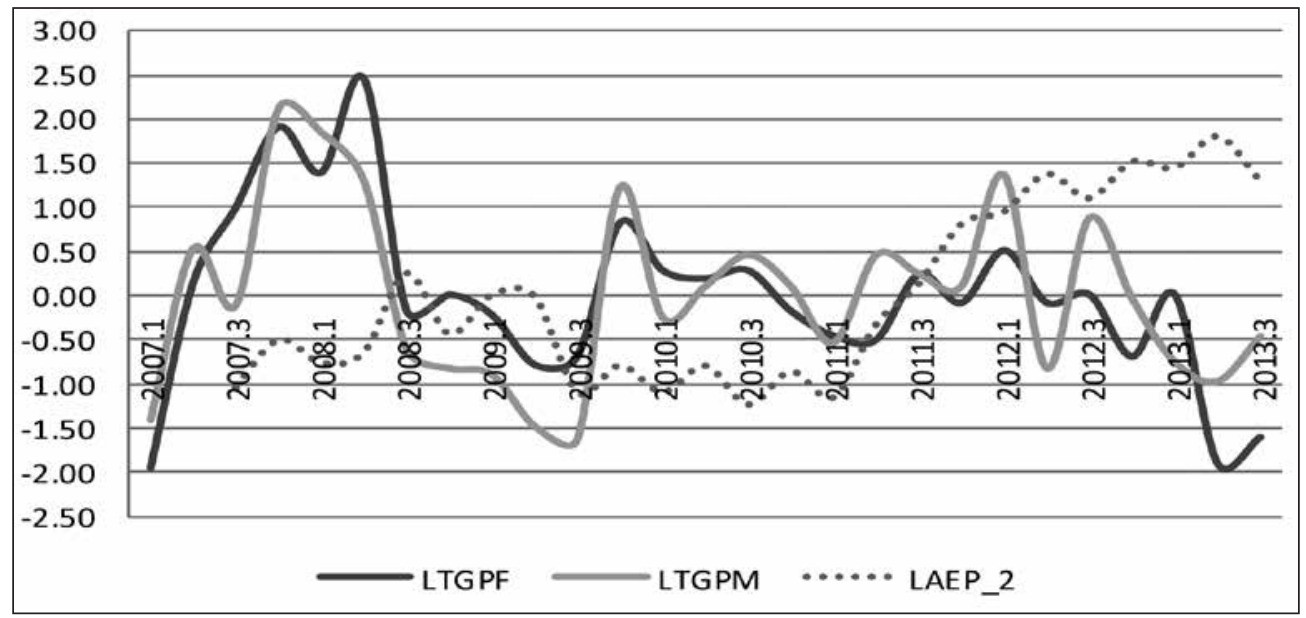

27 Fuente: Elaboración propia. LAEP 2: Logaritmo de actividad económica en Popayán rezagada dos períodos; LTGPF: Logaritmo de la tasa de participación laboral femenina; LTGPM: Logaritmo de la tasa de participación laboral masculina. Series normalizadas. 
encuentra que luego de una aceleración económica, la decisión de participar o no en el mercado laboral para los hombres no se ve afectada sustancialmente, a diferencia de la decisión de las mujeres, quienes en estos períodos son más propensas a salir del mercado laboral, ya que una buena situación económica, reflejada en mayores ingresos en el hogar, haría más prescindible la participación de ellas en el mercado laboral, además durante estos períodos se tendería a apreciar más el papel fundamental de ellas en el cumplimiento de labores de cuidado del hogar. Este planteamiento permitiría aceptar el efecto de la trabajadora excedente en el mercado laboral femenino de la ciudad de Popayán.

La relación entre la variación de los salarios, tomando como variable aproximada el salario real en la ciudad de Popayán (LSRP), ${ }^{28}$ y la variación de la tasa global de participación femenina (LTGPF) ${ }^{29}$ muestra una estrecha relación entre la variación del salario real y la variación de la tasa global de participación femenina en Popayán, presentando una correlación negativa de $-0,8803$, lo cual indica que conforme aumentan los salarios la tasa de participación laboral femenina disminuye considerablemente, y viceversa, si los salarios se comportan a la baja, las mujeres tenderán a aumentar en gran medida su participación en el mercado laboral, lo cual soporta nuevamente la hipótesis de la trabajadora adicional, lo cual se puede observar con mayor claridad entre mediados de 2009 y 2011.

Al analizar el comportamiento cíclico entre el nivel de salarios frente a la tasa global de participación femenina y masculina, estas últimas dos variables tienen una respuesta similar ante los cambios en el nivel salarial (Ilustración $15^{30}$ ). Para todo el período de análisis, se encuentra que conforme aumen- tan los salarios, en términos reales, la participación laboral tanto femenina como masculina disminuye, resaltando que la relación es más pronunciada en la participación de las mujeres, patrón que se acentúa más en la crisis.

\subsection{Test de igualdad de salarios}

Con el fin de complementar el análisis anterior, se estimó un test de igualdad entre los salarios de las mujeres y hombres ocupados durante el mes de marzo de 2013 para el departamento del Cauca, a partir de la información suministrada por la Gran Encuesta Integrada de Hogares (GEIH) realizada por el DANE. El test consiste en contrastar la hipótesis de igualdad entre estas dos variables, intentado responder si ctendrán hombres y mujeres ocupadas en el departamento del Cauca el mismo salario medio? ${ }^{31}$

Al observar los resultados, se encuentra que el salario medio obtenido por una mujer caucana ocupada es diferente al percibido por un hombre, para el período de análisis. Adicionalmente, al analizar los estadísticos por separado se percibe claramente la desigualdad en salarios, dado que mientras el salario promedio de una mujer caucana ocupada es aproximadamente $\$ 706.942$, para un hombre es $\$ 891.819$, lo cual constituye una brecha salarial a favor de los hombres alrededor de \$184.877. Para terminar, a partir de la desviación estándar se muestra una mayor homogeneidad en los salarios femeninos (\$719.015) que en los masculinos (\$1.187.417), lo cual se explica porque para el período de referencia, el mayor salario reportado por una mujer fue de $\$ 4.000 .000$, mientras que el salario más elevado devengado por un hombre caucano fue de $\$ 16.000 .000$.

27 Fuente: Elaboración propia. LAEP_2: Logaritmo de actividad económica en Popayán rezagada dos períodos; LTGPF: Logaritmo de la tasa de participación laboral femenina; LTGPM: Logaritmo de la tasa de participación laboral masculina. Series normalizadas.

28 Para construir esta variable se utilizó la información suministrada por el Departamento Nacional de Planeación (DNP) para el salario mínimo mensual legal vigente, y por el DANE para el comportamiento (a diciembre) del Índice de Precios al Consumidor (IPC) entre 2007 y 2013, de esta forma el análisis económico no se afecta por la variación de los precios durante el período observado, quedando los salarios expresados en valores del año 2013.

29 Esta serie fue necesaria agregarla en Ilustración 14, pasando de una temporalidad trimestral a una anual (ver Anexos).

30 Ver Anexos.

31 El resumen de los resultados se muestra en Tabla 2 (ver Anexos). 


\subsection{Análisis de cointegración entre la participación laboral femenina y el nivel de actividad económica en Popayán}

Con el fin de caracterizar las interacciones simultáneas entre las variables Tasa Global de Participación Femenina (TGPF), Tasa Global de Participación Masculina (TGPM) y el nivel de Actividad Económica en la ciudad de Popayán (AEP), se plantea una modelación tipo Vector Autorregresivo (VAR) ${ }^{32}$. Para estimar el modelo previamente se requiere practicar las pruebas de estacionariedad de las series, lo que garantizaría que los resultados de la modelación no llevarán a una regresión espuria ${ }^{33}$. Para ello se utilizó el Test de Dickey Fuller Aumentado ${ }^{34}$. Los resultados evidencian que las series utilizadas no presentan raíz unitaria, por lo tanto son estacionarias, lo cual garantiza que no se presentarán regresiones espurias ${ }^{35}$. De esta forma el modelo a estimar es el siguiente:

$$
X_{t}=\delta_{1} X_{(t-1)}+\delta_{2} X_{(t-2)} \delta_{3} X_{(t-3)}+\ldots+\delta_{k} X_{(t-k)}+\varepsilon_{t}(2)
$$

Donde:

$k=1,2,3, \ldots, 8$.

$\delta_{k}=a_{1 k} b_{1 \mathrm{k}} a_{2 k} b_{2 k}=$ Matriz de coeficientes $2 \times 2$

$X_{t}=A E P_{t} T G P F_{t}$

$\varepsilon_{t}=U_{t} W_{t}=$ Vector ruido blanco

No es relevante reportar los resultados obtenidos por el modelo VAR, ya que los coeficientes carecen de interpretación económica de fondo. La finalidad de plantear éste modelo es identificar las posibles relaciones de cointegración entre las variables que incorporan el modelo, utilizando el Test de Johansen $\left(\right.$ Tabla $\left.4^{36}\right)$. Asumiendo una tendencia lineal determinística entre las observaciones, pueden identificarse a través de la prueba relaciones estables de largo plazo entre las variables AEP y TGPF, para el período de análisis. Al realizar el mismo procedimiento entre las variables AEP y TGPM, los resultados arrojaron que no existe relación de cointegración entre estas dos variables, lo cual también es consistente con los hallazgos preliminares del estudio, donde se observa que la correlación entre AEP y TGPM es mucho menor, posiblemente debido al rol tradicional de los hombres como jefes de hogar, ellos independientemente del ciclo económico mantienen activa su participación laboral.

En síntesis, los resultados arrojados por el test de cointegración permiten validar una vez más la hipótesis de la trabajadora adicional, infiriendo que a largo plazo la decisión de participar o no en el mercado de trabajo de Popayán estará afectada por el nivel experimentado por la economía local, es decir que las variables AEP y TGPF mantienen una relación estable de largo plazo. Para validar que efectivamente es el nivel de actividad económica la que podría afectar la decisión de las payanesas de participar en el mercado de trabajo se implementó un test de causalidad de Granger (Engle \& Granger, 1987; Granger \& Newbold, 1974), el cual permite identificar relaciones de causalidad entre las variables explicati-

32 Según Novales (2013) un VAR es un modelo de ecuaciones simultáneas formado por un sistema de ecuaciones de forma reducida sin restringir, es decir que los valores contemporáneos de las variables del modelo no aparecen como variables explicativas en las distintas ecuaciones. El conjunto de variables explicativas de cada ecuación está constituido por un bloque de retardos de cada una de las variables del modelo. Que sean ecuaciones no restringidas significa que aparece en cada una de ellas el mismo grupo de variables explicativas. Este modelo es muy útil cuando existe evidencia de simultaneidad entre un grupo de variables, y que sus relaciones se transmiten a lo largo de un determinado número de períodos. Al no imponer ninguna restricción sobre la versión estructural del modelo, no se incurre en los errores de especificación que dichas restricciones pudieran causar al ejercicio empírico.

33 Es importante realizar éste procedimiento previo, dado que la existencia de una raíz unitaria en los errores de un modelo de regresión supone la no existencia de relaciones de cointegración entre las variables incluidas en un modelo, por lo que no podrían identificarse relaciones estables a largo plazo entre dichas variables. Una regresión espuria que se origina a partir de dos series temporales con raíz unitaria, llevaría a una interpretación errónea de la aparente relación entre ellas.

34 Los resultados de la prueba se muestran de forma resumida en la Tabla 3 (ver Anexos).

35 Sin embargo, las variables AEP y TGPF en niveles presentaron raíces unitaria, por lo cual fue necesario diferenciarlas dos veces, en cambio para la TGPM la estacionariedad se alcanzó a nivel aunque con 4 diferencias retardadas. Para la estimación del modelo VAR entre la actividad económica de Popayán (AEP) y la participación laboral femenina (TGPF), se obtuvo que el número de rezagos óptimo es 8.

36 Ver Anexos. 
vas y la variable a explicar. Para el presente caso, la prueba implica estimar el siguiente par de ecuaciones mediante mínimos cuadrados ordinarios (MCO):

$$
\begin{gathered}
A E P_{t}=\propto_{0}+\propto_{1} A E P_{(t-1)}+\propto_{2} A E P_{(t-2)} \\
+\beta_{1} T G P F_{(t-1)}+\beta_{2} T G P F_{(t-2)}+\varepsilon_{t}(3) \\
T G P F_{t}=\propto_{0}+\propto_{1} T G P F_{(t-1)}+\propto_{2} T G P F_{(t-2)} \\
\quad+\beta_{1} A E P_{(t-1)}+\beta_{2} A E P_{(t-2)}+\mu_{t}(4)
\end{gathered}
$$

La prueba consiste en determinar si los parámetros $\beta$ que acompañan a las variables retardadas AEP y TGPF, en las anteriores ecuaciones, son estadísticamente diferentes de cero (Tabla $5^{37}$ ). Los resultados ratifican que la causalidad es unidireccional, en este caso el nivel de actividad económica de Popayán (AEP) causa a la participación laboral femenina (TGPF), y no en sentido contrario. Se sugiere por lo tanto, que la variable AEP precede a la variable TGPF, lo que equivale a decir que dependiendo del nivel de actividad económica presentado aproximadamente seis meses antes en la ciudad de Popayán tendrán un impacto significativo en la decisión de participar en el mercado laboral. Lo anterior constituye una evidencia más de la hipótesis de la trabajadora adicional en la medida en que soporta la afirmación de que ellas tienen en cuenta el momento del ciclo económico para entrar al mercado laboral.

De otro lado, los resultados del test de causalidad de Granger (Engle \& Granger, 1987; Granger \& Newbold,1974) entre la actividad económica de Popayán (AEP) y la participación laboral masculina (TGPM) muestran que no se puede determinar causalidad en ningún sentido entre ambas variables, ésta independencia causal podría justificarse por el hecho que según datos censales, la mayoría de jefes del hogar en la ciudad de Popayán son hombres, de ésta forma su decisión de participar o no en el mercado laboral no dependerá del comportamiento del ciclo económico, ya que al ser cabezas del hogar deben mantener su participación laboral con el fin de obtener ingresos monetarios para el sostenimiento de sus familias.

\section{Conclusiones y recomendaciones}

La economía feminista ha develado la manera como la división socio-sexual del trabajo ha situado la crianza y el cuidado de las hijas y los hijos principalmente en las mujeres, sin que exista un reconocimiento por parte de la sociedad de lo que ha significado este trabajo del cuidado tanto al mercado como a las familias. El recargo de trabajo reproductivo sobre las mujeres ha constituido una de las barreras que se halla en la base de sus limitaciones para una efectiva inserción laboral.

En América Latina y en Colombia, prevalecen grandes brechas de género en los indicadores laborales. Estas desigualdades se fundamentan en las distintas barreras u obstáculos que las mujeres deben enfrentar en su vida laboral y que están relacionadas con aspectos como: i) barreras familiares y personales asociadas a la edad, a la maternidad, al estado civil, al trabajo reproductivo; ii) barreras en el ámbito educativo, asociadas a la segregación en la elección de estudios, las percepciones sociales sobre la fobia a la tecnología por parte de las mujeres, etc.; iii) barreras en el ámbito profesional asociadas a la segregación horizontal y vertical ${ }^{38}$ del mercado de trabajo; iv) barreras sociales asociadas a la dedicación del uso del tiempo para el trabajo reproductivo, la violencia intrafamiliar, la escasa participación social y política, etc.

Distintas autoras (Loayza, 1997; Benería, 2006; Carrasco, 2003) han planteado igualmente que en los

37 Ver Anexos.

38 La segregación horizontal se evidencia en el predominio femenino en ciertos sectores tradicionalmente feminizados, y la segregación vertical se refiere a una distribución desigual de mujeres y varones en la jerarquía ocupacional.

39 Es importante anotar que autoras como Quiroga (2009) retoman como hecho fundamental no las crisis financieras sino lo que llama la "crisis de reproducción", referida a la exclusión sistemática de amplios sectores de la población, especialmente las mujeres, del acceso a los recursos indispensables para satisfacer sus necesidades de reproducción, biológica y social. En América Latina esta crisis se expresa en un conjunto de situaciones que por la vía del desempleo, la pobreza, la precariedad y diversas formas de discriminación impiden a una significativa parte de la población tener capacidad de acceder a los recursos necesarios para garantizar el desenvolvimiento de su vida personal y familiar, y su inclusión como ciudadanos con plenos derechos. 
momentos de crisis del sistema económico, como las crisis financieras ${ }^{39}$ del 2000 o del 2008, a las mujeres de los sectores medios y populares se les impone la responsabilidad de administrar los cambios adversos y minimizar con sus cuidados y trabajo los efectos generados en los hogares. Es así como en estos momentos recesivos del ciclo económico, las mujeres duplican sus horas de trabajo fundamentalmente en actividades de economía informal y del cuidado y protección a sus familias, o en muchas ocasiones el mismo Estado les asigna las labores de cuidado que deben asumir a cambio de salarios precarios (un ejemplo claro es el de las Madres Comunitarias en Colombia). El cuidado de la vida, realizado por las mujeres en sus hogares, se traslada ahora también al escenario de lo público, y se las ve actuando como las cuidadoras comunitarias de los niños y niñas, cuidadoras de la salud de las personas de la comunidad, promotoras centrales de los procesos educativos a través de las juntas de "padres" de familia, o activistas incansables de los procesos de consecución o construcción de viviendas; todas éstas son actividades del cuidado que se realizan en el espacio público y que generalmente no son remuneradas o tienen salarios muy bajos, como se mencionó en párrafos anteriores.

La ciudad de Popayán no es ajena a este análisis conceptual que realiza la economía feminista, es así como la tasa de desempleo (TD) en Popayán fue en el periodo de referencia mayor para las mujeres que para los hombres. Existe una tendencia decreciente en la tasa para ambos sexos, aunque tal disminución fue más marcada para los hombres que para las mujeres. Es decir, que de mantenerse este ritmo de descenso en la TD para ambos sexos, la brecha tendería a aumentarse en la ciudad de Popayán. En términos etarios, la tasa de desempleo de las mujeres es mayor que la de los hombres para todos los rangos de edad. El desempleo más alto lo tienen las mujeres jóvenes (12 a 24 años de edad), con una tasa de desempleo promedio de $40 \%$ para todo el periodo, muy superior a la de los hombres de la misma edad que tienen 33,4\% de desempleo. La tasa de desempleo oculto casi se triplica en las payanesas, es decir, hay muchas más mujeres que hombres en calidad de "trabajadores desalentados" en la ciudad.
El trabajo de campo con mujeres en situación de pobreza en la ciudad de Popayán, evidencia los bajos niveles educativos y las limitaciones derivadas del mismo en aspectos básicos de lectoescritura y operaciones matemáticas, que reducen notablemente las posibilidades de desarrollar habilidades para el trabajo que les permitan vincularse a sectores de mayores niveles de productividad.

Las habilidades reportaron en los talleres focales se concentran fundamentalmente en los quehaceres domésticos. La preparación de alimentos, la confección, la decoración, entre otras, son actividades que extienden el rol doméstico para ubicarlo en el escenario del mercado laboral. Vale decir, que las actividades en las cuales las participantes dicen tener habilidades, son actividades relacionadas con la percepción cultural existente sobre lo que las mujeres deben "saber hacer", que en general se reduce a los oficios domésticos, para los cuales han sido entrenadas desde tempranas edades.

En los procesos de capacitación para el trabajo que se adelantan en la ciudad, prevalece un modelo cultural y tradicional de formación en el que ellas son capacitadas para actividades relacionadas, en su mayoría, con una extensión del trabajo doméstico, centrada en actividades de bajos niveles de productividad e inserción tecnológica, como culinaria; belleza y peluquería; manicure y pedicure; manipulación de alimentos, decoración; ética y protocolo, etc. Sin embargo, desde el 2010 se ha incrementado la capacitación a las mujeres en manejo básico de sistemas e inglés, como actividades diferenciadoras de la oferta de cursos mencionada anteriormente. Para el caso de los hombres, la oferta de capacitación para el trabajo está centrada en actividades que incorporan un importante factor tecnológico y son generalmente más demandadas en el mercado, por ejemplo, cursos en energética smartflex, electricidad, mantenimiento y operación de montacargas, sistemas, soldadura básica, mecánica de motos, interpretación de planos, entre otros.

La hipótesis de la trabajadora adicional también se puede validar cuando se compara la relación entre la variación del nivel de actividad económica y la variación de la tasa global de participación femenina 
y la masculina. Se encontró que para todo el período de análisis, el comportamiento de la economía local afecta más la decisión de las mujeres de participar en el mercado laboral, que la decisión masculina. Lo cual se puede explicar porque aproximadamente el $67 \%$ de los hogares payaneses está en cabeza de hombres, es decir que independientemente del nivel de actividad económica en la ciudad, los hombres por lo general mantienen estable su decisión de participar en el mercado laboral, a diferencia de ellas, que al considerarse trabajadoras secundarias (o de apoyo), su decisión de entrar o no al mercado de trabajo varía más, dependiendo de la dinámica económica en Popayán. Este comportamiento se acentúa más en períodos de aceleración económica, en los cuales posterior a un auge en la economía local, ellas disminuyen más su participación laboral en comparación con los hombres. Mientras que en períodos de crisis económica, las tasas de participación laboral se comportan de manera similar.

Cuando se analizan los efectos del comportamiento de los salarios reales en la participación laboral femenina de las payanesas, se aprecia una fuerte relación entre ambas variables, lo cual indica que si la evolución de los salarios es favorable para los hogares, las mujeres tenderán a disminuir considerablemente su decisión de participar en el mercado laboral, lo cual se constituye en una prueba de la hipótesis de la trabajadora excedente. Aunque la relación entre los salarios reales y la participación masculina en el mercado de trabajo de Popayán también es inversa, es menos pronunciada en comparación a la femenina, esta situación se acentúa más en las épocas de crisis económicas, reflejando nuevamente el cumplimiento de la hipótesis de la trabajadora adicional.

Al analizar la brecha salarial entre hombres y mujeres en el departamento del Cauca, se pudo establecer que es favorable para los hombres en aproximadamente \$184.877. Mostrando una mayor homogeneidad en los salarios femeninos que en los masculinos, lo cual se explica porque para el período de referencia, el mayor salario reportado por una mujer fue de \$4`000.000, mientras que el salario más elevado devengado por un hombre caucano fue de \$16`000.000, en el mes de marzo de 2013.
A la luz del panorama descrito cabe decir que en la actualidad, y en el mercado laboral de la ciudad de Popayán, existen evidentes desigualdades entre ambos sexos. A pesar de que se ha ido avanzando es preciso y necesario articular políticas de empleo específicas para las mujeres en tanto que parten de unas características y problemáticas diferentes. Por ello se hace urgente y necesaria la creación de un Centro Integral de empleo para las mujeres, dirigido por la Alcaldía de Popayán, desde donde se aborden cuatro ejes estratégicos para la empleabilidad femenina: i) formación para el trabajo y la empleabilidad; ii) intermediación laboral; iii) fomento del emprendimiento y el empresarismo; y iv) política integral para la equidad. Las acciones definidas en cada eje estratégico, deberán ser abordadas de manera coordinada entre distintos actores institucionales de carácter local, regional y nacional que operan en la ciudad, para avanzar efectivamente en un proceso de disminución del desempleo para las mujeres.

\section{Referencias}

Bakker, I. (1999). Dotar de género a la reforma de la política macroeconómica en la era de la reestructuración y el ajuste global. En: Carrasco, C. (ed.) Mujeres y economía. Barcelona, Icaria.

Benería, L. (2006). Trabajo productivo/reproductivo, pobreza y políticas de conciliación. Reunión internacional de expertas/ os en cohesión social, políticas conciliatorias y presupuesto público: una mirada desde el género. Ciudad de México, 2426 de octubre.

Campo, J. \& Sarmiento, V. (2011). Relación consumo de energía y PIB: evidencia desde un panel cointegrado de 10 países de América Latina entre 1971-2007. En: Munich Personal RePEc, Paper $\mathrm{N}^{\circ}$ 31772: 1-22.

Carrasco, C. (2003). Mujeres y economía: nuevas perspectivas para viejos y nuevos problemas. España: Editorial Icaria.

Engle, R. \& Granger, C. (1987). Co-integration y error- correction: representation, estimation y testing. En: Econometrica, Econometric Society, 55 (2): $251-276$.

Granger, C. \& Newbold, P. (1974). Spurious regressions in econometrics. En: Journal of Econometrics, Elseiver, 2: 111 - 120.

Loayza, N. (1997). El trabajo de las mujeres en el mundo global, paradojas y promesas. Centro de Promoción de la Mujer Gregoria Apaza, La Paz, Bolivia.

Magazzino, C. (2011). Energy consumption y aggregate income in Italy: cointegration y causality analysis. En: Munich Personal RePEc Archive, $\mathrm{N}^{\circ} 28494$.

Osorio, R. (1997). Algunos aspectos sobre el mercado laboral. una aproximación teórica y empírica. En: Revista Universidad Eafit, Universidad Eafit, 33 (106): 97-120.

Ozturk, I. (2010). A literature survey on energy - growth nexus. En: Energy Policy, Elseiver, 38: 340-349. 
Quiroga, N. (2009). Economías feminista, social y solidaria. Respuestas heterodoxas a la crisis de reproducción en América Latina. En: Revista de Ciencias Sociales, Flacso Ecuador, (33): 77-89.

Safa, H. (1992). De mantenidas a proveedoras. Puerto Rico: Editorial Universidad de Puerto Rico.

Safa, H. (2002). La mujer en América Latina, El impacto del cambio socioeconómico. Universidad de Guadalajara, Instituto Latinoamericano de Servicios Legales Alternativos.

Santamaría, M. \& Rojas, N. (2001). La participación laboral: ¿Qué ha pasado y qué podemos esperar?. En: Archivos de Macroeconomía, Banco de la República, (146): 1-49.
Sarmiento, L. \& Vargas, H. (2002). El trabajo de las mujeres en Colombia. Bogotá: Edición Corporación Viva la Ciudadanía. Squialli, J. (2007). Electricity consumption and economic growth: bounds and causality analyses of OPEC countries. En: Energy Economics, Elseiver, 29: 1192 - 1205.

Velásquez, S. (2010). Ser mujer jefa de hogar en Colombia. En: Revista de Información Básica, Departamento Administrativo Nacional de Estadística (DANE). $8^{\circ}$ Edición. 


\section{ANEXOS}

Ilustración 10. Ciclo de la participación laboral masculina y femenina en Popayán. Filtro de Hodrick-Prescott normalizado. Periodo 2007-1 - 2013-31

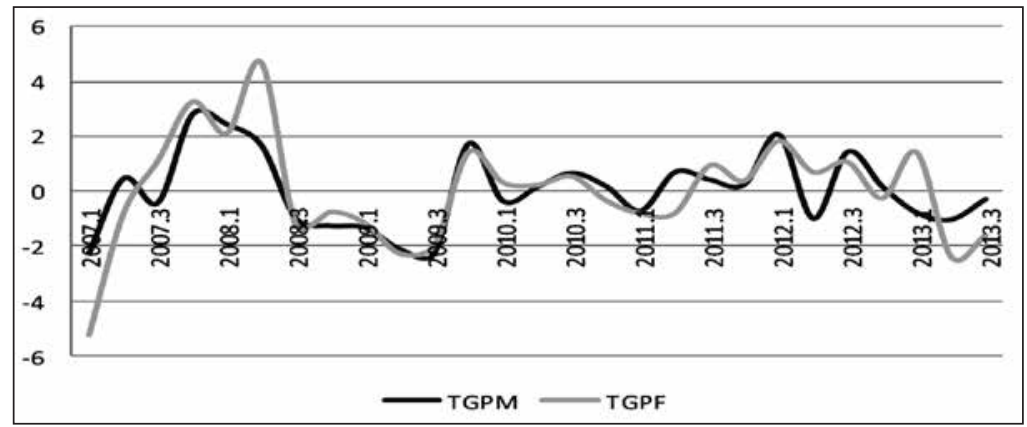

Ilustración 11. Ciclo de la participación laboral femenina en Popayán. Filtro de Hodrick-Prescott normalizado. Periodo $2007-1-2013-3^{2}$

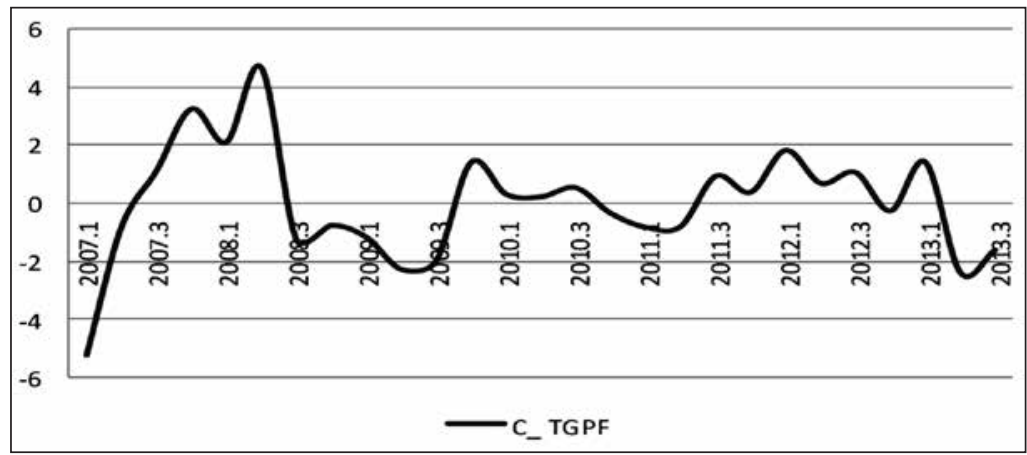

Ilustración 12. Ciclos TGP femenina y TD masculina en Popayán. Filtro de Hodrick-Prescott normalizado. Periodo 2007$1-2013-3^{3}$

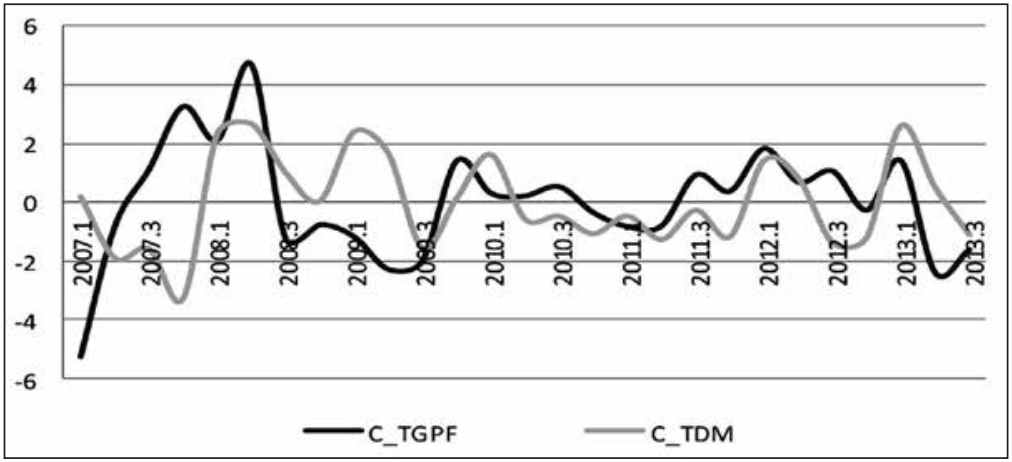

Fuente: Elaboración propia a partir de DANE. TGPM: Tasa global de participación masculina; TGPF: Tasa global de participación femenina.

2 Fuente: Elaboración propia a partir de DANE. C_TGPF: Ciclo de la tasa global de participación femenina.

3 Fuente: Elaboración propia. C_TGPF: Ciclo de la tasa global de participación femenina; C_TDM: Ciclo de la tasa de desempleo masculina. 
Ilustración 13. Variación del nivel de actividad económica y la TGP femenina de Popayán. Contemporáneas y rezagadas. Periodo 2007-1 - 2013-34

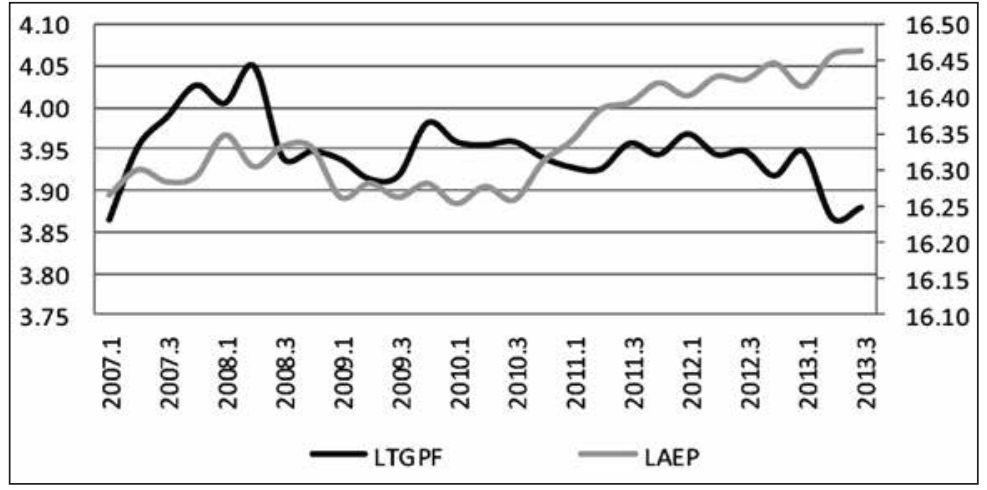

Ilustración 14. Variación de los salarios y la TGP femenina de Popayán. Periodo 2007-1 - 2013-35

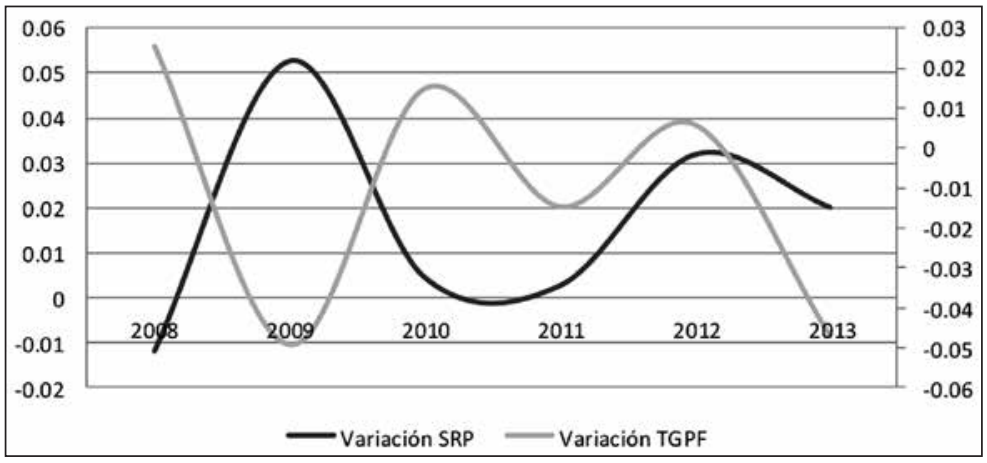

Ilustración 15. Ciclo del salario real, TGP femenina y masculina de Popayán. Anual 2007 - $2013^{6}$

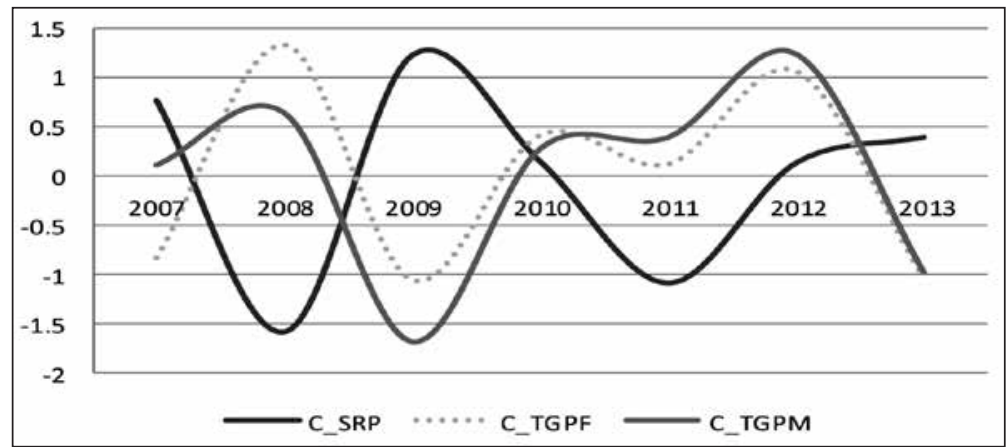

4 Fuente: Elaboración Propia. LAEP: Logaritmo de la actividad económica en Popayán; LTGPF: Logaritmo de la tasa de participación laboral femenina.

5 Fuente: Elaboración propia. SRP: Salario real en Popayán; TGPF: Tasa global de participación femenina.

6 Fuente: Elaboración propia. C_SRP: Ciclo salario real en Popayán; C_TGPF: Ciclo de la tasa global de participación femenina; C_TGPM: Ciclo de la tasa globāl de participación masculina. 
Tabla 2. Test de igualdad entre ingresos femeninos y masculinos en el departamento del Cauca. Marzo $2013^{7}$

\begin{tabular}{|c|c|c|}
\hline Estadísticas & INGF & INGM \\
\hline F estadístico & \multicolumn{2}{|c|}{6,158295} \\
\hline F estadístico (probabilidad) & \multicolumn{2}{|c|}{0,0133} \\
\hline Media & 706.942 & 891.819 \\
\hline Desviación estándar & 719.015 & 1.187 .417 \\
\hline Máximo & 4.000 .000 & 16.000 .000 \\
\hline
\end{tabular}

Tabla 3. Test Dickey-Fuller aumentado ${ }^{8}$

\begin{tabular}{|c|c|c|}
\hline Variable & ADF Estadístico & $\begin{array}{c}\text { Valor crítico* } \\
\text { (MacKinnon) }\end{array}$ \\
\hline$D(A E P, 3)$ & $-3,989842$ & $-3,633$ \\
\hline$D(T G P F, 3)$ & $-4,176454$ & $-3,633$ \\
\hline$D(T G P M)$ & $-4,316046$ & $-3,633$ \\
\hline
\end{tabular}

Tabla 4. Test de cointegración de Johansen ${ }^{9}$

\begin{tabular}{|c|c|c|c|c|}
\hline \multicolumn{5}{|c|}{$\begin{array}{l}\text { Sample: 2007:1 2013:3 } \\
\text { Included observations: } 24 \\
\text { Test assumption: Linear deterministic trend in the data }\end{array}$} \\
\hline \multicolumn{5}{|c|}{$\begin{array}{l}\text { Series: AEP TGPF } \\
\text { Lags interval: } 1 \text { to } 2\end{array}$} \\
\hline & Likelihood & 5 Percent & 1 Percent & Hypothesized \\
\hline Eigenvalue & Ratio & Critical Value & Critical Value & No. of $\mathrm{CE}(\mathrm{s})$ \\
\hline 0,497332 & 16,64239 & 15,41 & 20,04 & None * \\
\hline 0,005592 & 0,13458 & 3,76 & 6,65 & At most 1 \\
\hline
\end{tabular}

${ }^{*}\left({ }^{* *}\right)$ denotes rejection of the hypothesis at $5 \%(1 \%)$ significance level

L.R. test indicates 1 cointegrating equation(s) at $5 \%$ significance level

Tabla 5. Test de causalidad de Granger. TGPF, AEP, TGPM y AEP de Popayán. Periodo 2007-1 - 2013-310

\begin{tabular}{|c|c|c|}
\hline Hipótesis nula & F estadístico & Probabilidad \\
\hline TGPF no causa en sentido Granger a AEP & 0,02134 & 0,97891 \\
\hline AEP no causa en sentido Granger a TGPF & 4,87809 & 0,01882 \\
\hline TGPM no causa en sentido Granger a AEP & 0,31316 & 0,73465 \\
\hline AEP no causa en sentido Granger a TGPM & 0,74185 & 0,48889 \\
\hline
\end{tabular}

7 Fuente: Elaboración propia, a partir de la GEIH - DANE, marzo 2013. INGF: Ingresos de las mujeres ocupadas; INGM: Ingresos de los hombres ocupados.

8 Fuente: Elaboración propia. D(AEP,3): Nivel de actividad económica de Popayán (AEP) en segunda diferencia y 2 diferencias retardadas; (TGPF,3): Tasa global de participación femenina (TGPF) en segunda diferencia y 2 diferencias retardadas; D(TGPM): Tasa global de participación masculina (TGPM) a nivel y 4 diferencias retardadas; ADF: Dickey Fuller Aumentado; Valor crítico*: Valor crítico al $5 \%$ de significancia.

9 Fuente: Elaboración propia.

10 Fuente: Elaboración Propia. TGPF: Tasa global de participación femenina; AEP: Actividad económica en Popayán; TGPM: Tasa global de participación masculina. 